\title{
What Accounts for the Variation in COVID-19 Vaccine Hesitancy in Eastern, Southern and Western Europe?
}

\author{
Dimiter Toshkov ${ }^{1}$ \\ Institute of Public Administration, Leiden University, the Netherlands
}

This version: 11 January 2022

\begin{abstract}
Attitudes towards vaccination have proven to be a major factor determining the pace of national COVID-19 vaccination campaigns throughout 2021. In Europe, large differences in levels of vaccine hesitancy and refusal have emerged, which are highly correlated with actual vaccination levels. This article explores attitudes towards COVID-19 vaccination in 27 European countries based on data from Eurobarometer (May 2021). The statistical analyses show that demographic variables have complex effects on vaccine hesitancy and refusal. Trust in different sources of health-related information has significant effects as well, with people who trust the Internet, social networks and 'people around' in particular being much more likely to express vaccine skepticism. As expected, beliefs in the safety and effectiveness of vaccines have large predictive power, but - more interestingly - net of these two beliefs, the effects of trust in Internet, online social networks and people as sources of health information are significantly reduced. This study shows that the effects of demographic, belief-related and other individual-level factors on vaccine hesitancy and refusal are context-specific. Yet, explanations of the differences in vaccine hesitancy across Europe need to consider primarily different levels of trust and vaccine-relevant beliefs, and to a lesser extent their differential effects.
\end{abstract}

\section{Keywords}

Covid-19, media consumption, public opinion, trust, vaccination, vaccine hesitancy

${ }^{1}$ Corresponding author: d.d.toshkov@,fgga.leidenuniv.nl ORCID: 0000-0002-7444-9340. 


\section{Introduction}

The approval of vaccines against COVID-19 in late 2020 in the United States and Europe brought hope to citizens and policy-makers that the raging pandemic soon will be curtailed and that harsh restrictive societal lockdowns will no longer be necessary to contain the spread of the virus. Moving with different speeds, most European countries rolled out mass vaccination campaigns throughout 2021. While in the beginning insufficient vaccine supply was the limiting factor for the success of the vaccination efforts, soon a different obstacle became evident - namely, vaccine hesitancy amongst some parts of the population.

Vaccine hesitancy, or the unwillingness to get vaccinated, is not a new phenomenon. Trends of increasing vaccine hesitancy among different social groups in various countries had been noted by social scientists and public health experts already (i.a. Yaqub et al. 2014). However, the scale of vaccine hesitancy in many parts of Europe was still surprising, especially given a context where the virus and the associated disease targeted by the vaccines presented such a clear and immediate danger. Moreover, vaccine hesitancy proved largely resistant to government appeals and only weakly responsive to policy interventions.

As of May 2021, very significant differences in vaccine hesitancy in different regions of Europe emerged. Figure 1 shows the rankings of 27 members of the European Union with respect to the country averages of vaccine refusals (respondents who declare that they will never get a COVID-19 vaccine) and vaccine hesitancy (a broader concept that also includes those who say they will delay getting a vaccine or have not decided yet). The highest levels of vaccine refusal and hesitancy were observed in Bulgaria - where more than half of the population expressed hesitancy or refusal to vaccinate, followed by Latvia and Slovenia. The lowest levels were observed in Spain and Malta. Altogether, the top 10 vaccine-sceptic populations in the European Union were in the Eastern part of the continent. The Southern European countries were dispersed in the middle (Cyprus, Greece) and bottom of the ranking. From the Western European countries, Austria, France and Luxembourg exhibited relatively high levels of vaccine hesitancy (between $27 \%$ and $23 \%$ of the population) and refusal (between $12 \%$ and $11 \%$ ). 


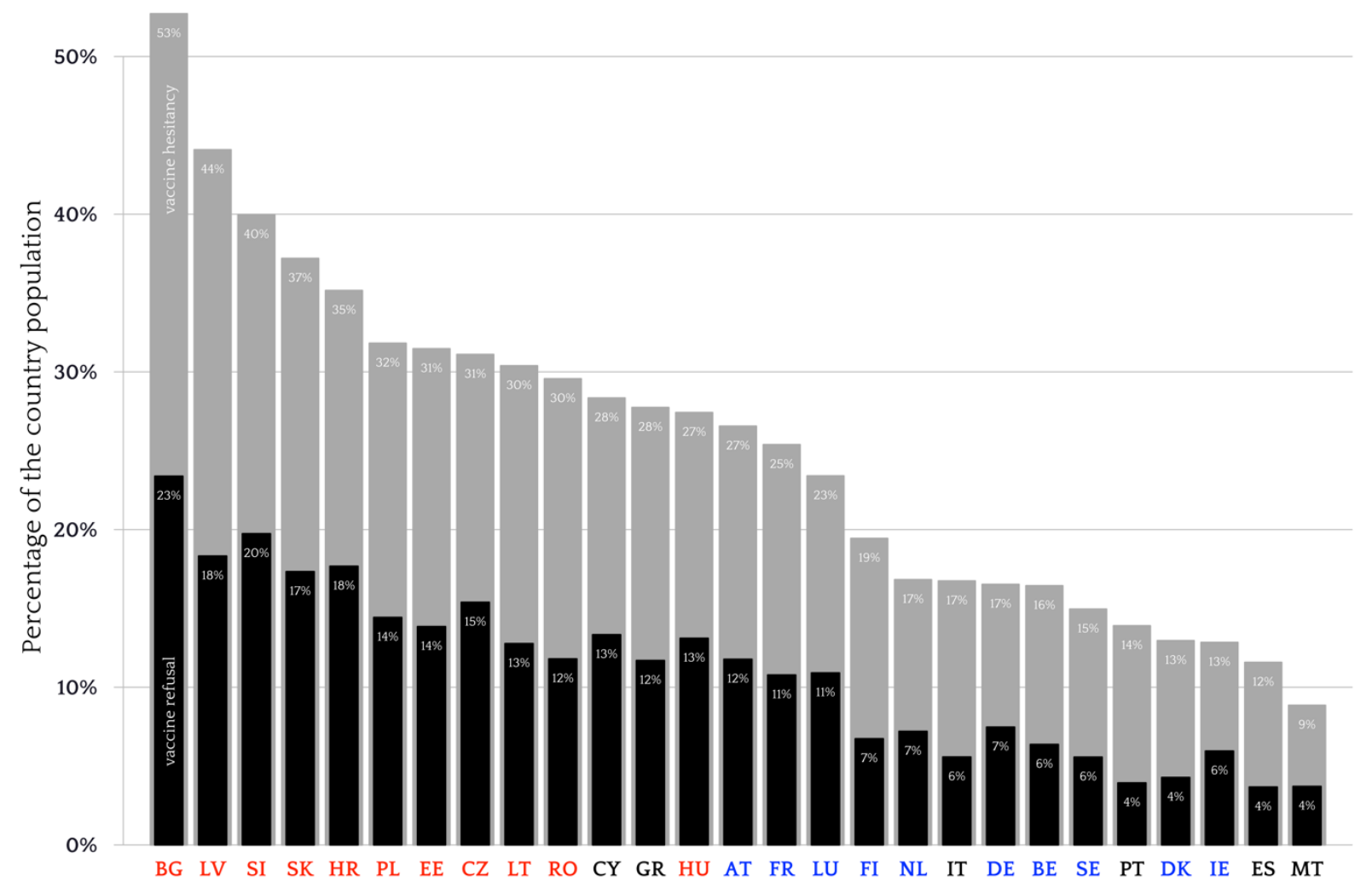

Figure 1. Prevalence of vaccine refusal (black bars) and hesitancy (dark-grey bars) in the Europe Union, per country. Country names are coloured per region (Eastern in red, Western in blue and Southern in black). Estimates are adjusted by post-stratification weights. Data: Flash Eurobarometer 494, May 2021.

The importance and policy relevance of these attitudes is demonstrated by their very strong relationship with actual levels of vaccine uptake ${ }^{2}$. At the country level, with 27 observations, the correlation is -0.88 and the link is quite linear (see Figure 2 for the plot), with Romania being a notable outlier, having too low vaccination uptake even considering its relatively vaccine-hesitant population. Given the societal importance of vaccine hesitancy as a personal disposition and as a social phenomenon, we should aim to identify the factors that can predict and explain why some people refuse to get or hesitate about getting a COVID-19 vaccine. Existing scholarship already draws attention to the problem of vaccine hesitancy (i.a. Yaqub et al. 2014) and provides important insights

\footnotetext{
2 The correlation between self-reported vaccination levels and actual vaccine uptake based on official administrative data is not very high (0.28), but the survey question about vaccination status is ambiguous, as it does not specify whether a single vaccination counts or two doses are necessary.
} 
about its possible causes and predictors (Lindholt et al. 2021; Crawshaw et al. 2021). For example, Sallam draws attention to the low levels of COVID-19 vaccine acceptance in the Middle East, Russia, Africa and some Eastern European countries (Sallam 2021). Obregon et al. (2020) also note that the prevalence in vaccine hesitancy has been increasing in countries in Eastern Europe and Central Asia. Neumann-Böhme et al. (2020) draw attention to high and increasing vaccine hesitancy with regard to COVID-19 vaccines.

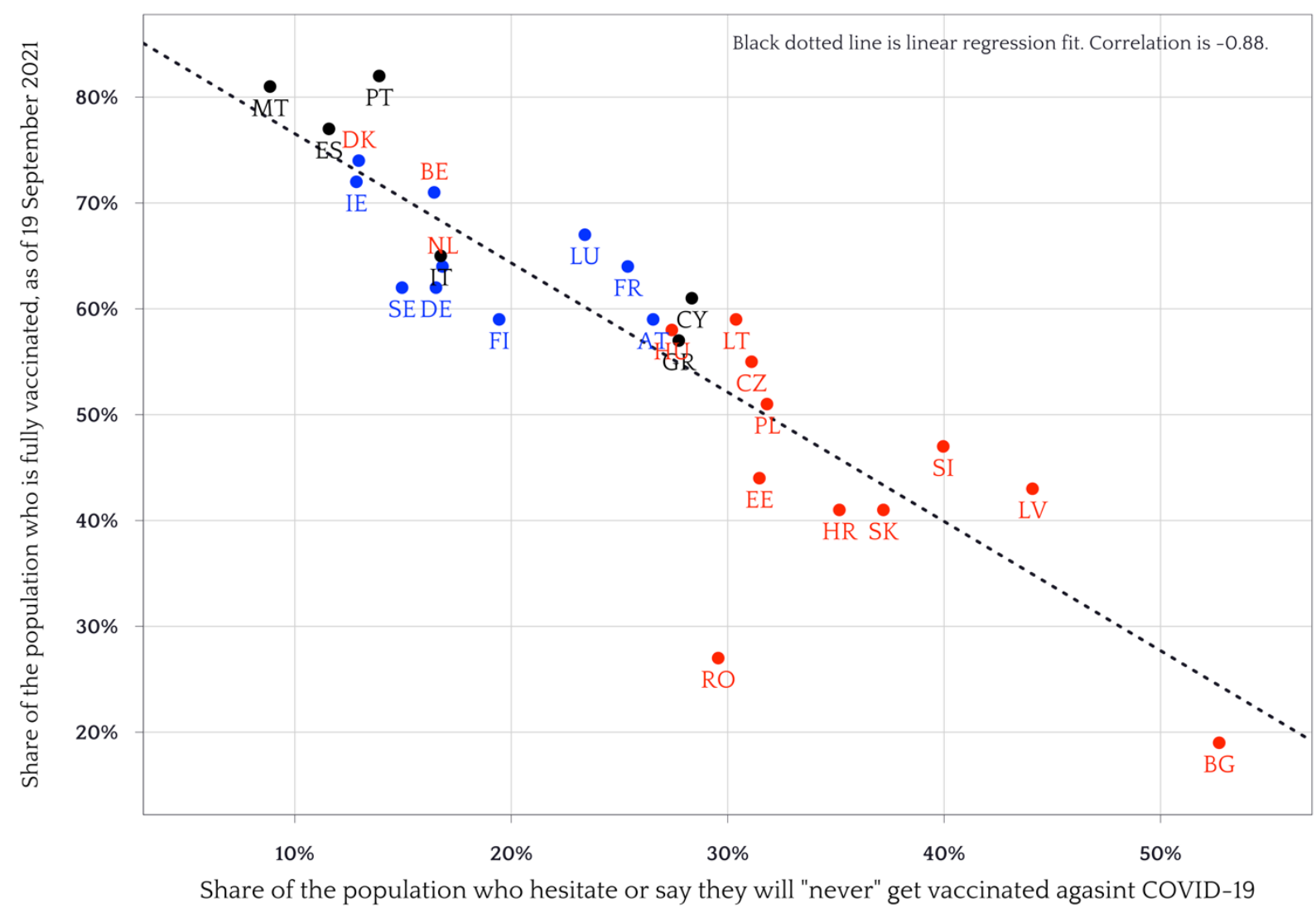

Figure 2. Relationship between vaccine hesitancy and vaccination rates in 28 member states of the European Union. Attitude data: Flash Eurobarometer 494, May 2021. Vaccination data: Our World in Data, as of 19 September 2021.

In the context of COVID-19, scholars have also tested the effects of particular interventions, such as science-based, moral frames, and social norm messages (Green et al. 2021), as well as providing knowledge about herd immunity through vaccination (Pfattheicher, Petersen, and Böhm 2021).

This article contributes to the existing scholarship by providing a comprehensive, comparative exploration of the attitudes of Europeans towards COVID-19 vaccines at an important moment of 
time, near the start of the mass vaccination campaigns in 2021. The analysis looks in detail at the individual-level associations of vaccine refusal and hesitancy with demographic variables, such as age, education, gender, place of residence and occupation, with trust in different information sources, and with COVID-19-related beliefs and experiences. The study also tests the mediating roles of (a) trust in Internet as a source of information and (b) beliefs related to vaccine safety in translating the effects of age and education on vaccine hesitancy.

The differences in levels of vaccine hesitancy across the three broadly-defined regions in Europe (Eastern, Western and Southern) are of particular interest for the article. To address possible explanations about the differences, the empirical analyses test whether the levels as well as the effects of the demographic, information-based and COVID-19-related variables differ in the three regions via the inclusion of interaction effects in the statistical models.

The empirical analyses find that male, older, and more educated respondents, living in cities and working as employees are less likely to express hesitancy and refusal towards COVID-19 vaccines. Trust in the EU, national and local governments, health authorities and the medical profession as sources of reliable information on vaccines is predictive of lower vaccine hesitancy and refusal, while trust in the Internet, online social networks and 'people around' have the opposite effects. Beliefs that vaccines are safe and effective, as well as fear from COVID-19, knowing someone who has been sick from COVID-19 and not having been infected yourself have large negative associations with vaccine hesitancy and refusal. Importantly, while the levels of these variables differ significantly across Eastern, Southern, and Western Europe, their effects are very similar across the three regions, with some exceptions, such as the effect of education, which is much smaller in Southern Europe. The mediation analyses show that age and education have both direct (in Eastern and Western Europe) and indirect effects via trust in the Internet as a source of information and vaccine-related beliefs.

The main contributions of the article are three. First, it provides a comprehensive analysis of the influence of a large number of demographic and trust-related variables, as well as COVID-related experiences and beliefs for a large number of European states. Second, it identifies the difference in levels of vaccine hesitancy predictors in Eastern Europe rather than differential effects of these variables as potential explanations for the much higher levels of vaccine hesitancy and refusal in the region. Third, it shows that the effects of age and education are both direct and indirect and that trust in Internet sources of information also has direct and indirect - via vaccine-related beliefs - effects. 


\section{Theoretical considerations}

Based on existing literature we can identify several clusters of variables that might be significant predictors of vaccine hesitancy with respect to COVID-19 vaccines. The first cluster refers to demographic factors, the second one refers to trust in different sources of vaccine-relevant information and the third one refers to experiences with and beliefs about COVID-19 itself.

The large comparative study of 19 countries reported in Lazarus et al. (2020) reports that several demographic factors are significantly associated with vaccine hesitancy (see also Salomoni et al. 2021; Lindholt et al. 2021). There are well-documented differences in vaccine hesitancy between men and women. The associations, however, are complex and differ across studies, with some finding the women are more likely to be vaccine hesitant (also with respect to COVID-19 vaccines) (Lazarus et al. 2020) and others finding the opposite pattern (El-Elimat et al. 2021; Paul, Steptoe, and Fancourt 2021). Lewis and Duch report that 'Across 16 studies, men consistently express lower perceived risk of contracting COVID-19 and less concern about the potential health consequences', and, at the same time, 'risk perceptions are positively correlated with self-reported propensity toward protective behaviors.' (Lewis and Duch 2021). In a big comparative study, Bergman et al. (2021) concluded that altogether women have higher levels of vaccine refusal, but that in Hungary, Portugal and Switzerland the opposite was true.

With respect to age, younger people (than 65) are more likely to be vaccine deniers (Bergmann et al. 2021). Lazarus et al. (2020) also find that people older than 50 are more likely to accept vaccines in most countries they study, with the important exception of China. There is also evidence that in Jordan older people are more likely to be vaccine hesitant (El-Elimat et al. 2021).

The effect of education is even more complex and heterogeneous. According to Lazarus et al. (2020), higher education is positively associated with vaccine acceptance in Ecuador, France, Germany, India, and the US, but negatively associated in Canada, Spain, and the UK. There is further evidence that higher education is associated with lower vaccine hesitancy in the UK (Paul, Steptoe, and Fancourt 2021) and in the US (Stroope et al. 2021). For the US, Rhodes et al. find that 'welleducated parents were more likely to plan to vaccinate themselves and their children' (Rhodes et al. 2020).

In-depth studies convincingly argue that vaccine hesitancy is not necessarily a low education phenomenon. One study identifies five groups that are more likely to be under-vaccinated: Orthodox Protestant communities, Anthroposophists, Roma, Irish Travellers, and Orthodox Jewish communities. The Antrhroposophists are particularly interesting, because they tend to be highly 
educated. Their vaccine hesitancy stems from a belief that 'a healthy life, a good nutrition (e.g., breastfeeding for babies), and a safe environment (e.g. mothers who stay at home to take care of their children)' lead to a strong immune system of their children, which can better fight infections diseases so that vaccine are not necessary (Fournet et al. 2018).

Relatedly, an in-depth study of more-educated Dutch parents found a 'neoromantic' set of attitudes towards vaccines among them, which 'focuses on deriving truth through intuition and following a "natural" path and informs a risk typology: embracing (refusing) "natural" ("unnatural") risks such as “childhood diseases" ("pharmaceutical substances”).' In addition, there was a second set of common attitudes: 'A critical-reflexive repertoire [that] centers on scientific methods but is skeptical about the scientific consensus and informs a risk calculation: opting for the choice perceived to bear the smallest risk.' ('Ten Kate, Koster, and Van der Waal 2021)

In addition to age, sex, and education, other socio-demographic factors that have been shown to be possible predictors and causes of vaccine hesitancy include income and occupation. For example, in Jordan the employed were less likely to accept COVID-19 vaccines (El-Elimat et al. 2021). Lower income was associated with higher distrust of vaccines in the UK (Paul, Steptoe, and Fancourt 2021). In fact, according to Bergmann et al (2021), the economic situation was the strongest predictor of vaccine hesitancy and refusal, with significant differences between '(self-)employed, retired and respondents with other (non-)working status'.

The second cluster of variables that are potential predictors of vaccine hesitancy relate to the source of medical and vaccine-related information that people consider trustworthy (Yaqub et al. 2014; Vosheva et al. 2021), which is related to (mis)information about the safety and effectiveness of vaccines. Overall, trust in doctors and nurses was strongly associated with trust in vaccines, but relatively to a smaller extent in Europe than in other parts of the world, according to data from the 2018 Wellcome Global Monitor Report (Obregon et al. 2020). In Italy, efforts of the scientific community with the support of the Ministry of Health have helped curb beliefs in the harmfulness of vaccines (Paladini et al. 2021). According to the comparative study of Lindholt et al. (2021), vaccine hesitancy was associated with 'lack of trust in authorities and scientists, conspiratorial thinking, and a lack of concern about COVID-19'.

But people get information about vaccines from various sources, not restricted to the medical community. Television was identified as the primary source for information about vaccination in a recent study (Anastasiou and Heger 2021). But the importance of the Internet and online social networks as sources for health-related information is growing. The usage, however, is heterogeneous. 
Alvarez-Galvez et al. find that significant differences exist with regard to 'gender, age, education, longterm illness and health-related knowledge'. The study found an association between a poor health status and a higher use of the Internet for health purposes, but, importantly, only for the subset of people with chronic health conditions (Alvarez-Galvez et al. 2020). Information from social media was one of the main causes of vaccine hesitancy' with regard to measles (Wawrzuta et al. 2021; see also Wilson and Wiysonge 2020).

The political character of the media consumed by the citizens is important as well, at least in the US. In a national 3-wave longitudinal survey of 883 US respondents running from March to November 2020, researchers found that '[a]lthough users of conservative media supported vaccination and trusted the CDC at the outset of the study, continued exposure to conservative media reduced support for both. Increasing use of mainstream print was associated with less endorsement of pandemic conspiracy beliefs. Viewers of mainstream television news did not exhibit change in pandemic conspiracy beliefs over time' (Romer and Jamieson 2021). Relatedly, in the US conspiracy beliefs were found to mediate the effects of demographic variables (Stroope et al. 2021).

Given the importance of information, it is unsurprising that several experimental studies find that vaccination intentions can be affected by messages promoting vaccines based on science-based, moral, and social norm frames (Green et al. 2021) and by messages emphasizing empathy and herd immunity effects (Pfattheicher, Petersen, and Böhm 2021).

The third cluster of theoretically-important variables relate to beliefs about (COVID-19) vaccines and beliefs about and experiences of the disease itself. Those who believe vaccines are safe have been found to be more likely to access COVID-19 vaccines in Jordan (El-Elimat et al. 2021). Poor knowledge of COVID-19 and compliance with government COVID-19 guidelines were predictive of distrust in vaccines in the UK (Paul, Steptoe, and Fancourt 2021). Fear of vaccine side effects was the most often mentioned complaint about COVID-19 vaccination (Marco-Franco et al. 2021). Another cross-country study also finds that fear and personal perceptions of risk of COVID19 infection are major factors related to the willingness to vaccinate (Vosheva et al. 2021, see also Phillips et al. 2021). Knowing someone who was severely affected by the virus increased the willingness to be vaccinated (Bergmann et al. 2021). Prior to COVID-19, studies had also found that knowledge about the effectiveness and safety of vaccination increases the probability of having received a vaccination in the past five years (Anastasiou and Heger 2021).

All factors and studies considered so far work at the individual level. There is less work focused on explaining cross-country differences in vaccination attitudes. Sturgis et al. (2021) conclude that '[i]n 
countries with a high aggregate level of trust in science, people are more likely to be confident about vaccination, over and above their individual-level scientific trust. Additionally, ... societal consensus around trust in science moderates these individual-level and country-level relationships' (Sturgis, Brunton-Smith, and Jackson 2021).

The (post)communist background of countries has also been linked to higher levels of vaccine hesitancy. The explanation lies 'in a wider distrust in public and state institutions resulting from the exposure to Soviet communism.', according to Costa-Font et al. (2021). Studies of particular postcommunist countries exist as well. In Slovenia higher intention to get vaccinated is associated with men, older respondents, physicians and medical students, respondents who got the influenza vaccination, those who knew someone who had gotten hospitalised or died from COVID-19 and those who have more trust in experts, institutions and vaccines.' In addition, nurses and technicians were found to be less likely to get vaccinated (Petravić et al. 2021). In Poland, the fear the fear of vaccines' side effects, beliefs in conspiracy theories and physical fitness were identified as major predictors of COVID_19 vaccine hesitancy (Sowa et al. 2021). The broader phenomenon of vaccine hesitancy in Poland has been linked to the political phenomenon of populism in Eastern Europe, and the anti-Enlightenment and anti-Western shift in the public sphere in the region ( $\dot{Z} u k$, $\dot{Z} u k$, and Lisiewicz-Jakubaszko 2019) and with the spread of fake news (Waszak, Kasprzycka-Waszak, and Kubanek 2018).

Overall, the existing literature identifies a large number of demographic and other variables with significant associations with vaccine hesitancy and refusal. The effects of these variables, however, are very heterogeneous, which necessitates cross-country comparative analyses that can account for how the effects differ across countries and regions. Furthermore, most of the studies do not attempt to establish the causal nature of the observed associations, which requires that we pay attention to the possible casual ordering and confounding of the variables included in the study. To address these limitations, the analyses reported below cover a large number of countries, allow the effects to vary across regions, and introduce mediation models in which trust in sources of vaccinerelated information and vaccine-related beliefs mediate the effects of demographic variables, such as age and education.

\section{Data and operationalization}

The empirical part of this article analyzes the data from Flash Eurobarometer 494. This comparative survey of public attitudes was fielded in May 2021 at the request of the European Commission by 
Ipsos European Public Affairs, Brussels. The survey was based on quota-based nationallyrepresentative samples from the 27 member states of the EU. The interviews were web-based and conducted via self-administered questionnaires. The sample size for most countries was around 1,000 respondents (Malta, Cyprus and Luxembourg had a smaller number of respondents at around 515 each).

\section{Outcome variables}

The main outcome variables of interest are COVID-19 vaccine hesitancy and vaccine refusal. Respondents are considered 'vaccine hesitant' if they responded that they will 'Never' get vaccinated against COVID-19 or will get vaccinated 'Later' (but not 'some time in 2021') or 'Don't know' or prefer not to answer the question. Vaccine refusal refers only to those who declare that they will 'Never' get vaccinated. The original formulation of the survey question is: 'When would you like to get vaccinated against COVID-19 (coronavirus)?’ and the remaining answer categories, in addition to the ones mentioned above, are 'As soon as possible', 'Some time in 2021', and 'I have already been vaccinated'.

\section{Demographic predictors}

The main demographic predictors of interest are age (measured in years), education (measured as the age at which full-time education was stopped), gender, place of residence ('Large town/city' vs. 'Small or medium-sized town' and 'A rural area of village'), and professional occupation (with four categories: 'Self-employed', 'Employee', 'Manual worker', and 'Without a professional activity').

\section{Trust}

Trust in different authorities with respect to COVID-19-related information is measured via the question 'Among the following sources, which ones would you trust more to give you reliable information on COVID19 vaccines?', with multiple answers possible from the following categories: 'The European Union', 'The National Government', 'The National Health Authorities', 'The regional or local public authorities', 'Health professionals, doctors, nurses and pharmacists', 'Media (television, radio, newspapers', 'Websites', 'Online social networks', 'People around you (colleagues, friends and family)' and 'Don't know').

\section{Vacine-related beliefs}


Two vaccine-related beliefs are measured: 'Vaccines are safe' and 'Vaccines are effective'. Originally, answers to both are recorded on 4-point agreement scales, which have been collapsed in two categories ('Agree totally or tend to agree' vs. 'Disagree totally or tend to disagree’).

\section{Knowledge about and attitudes towards COVID-19}

Several items related to knowledge about COVID-19 are used: whether the respondent knows people who have tested positive or have been ill, whether the respondent has tested positive or has been ill, and whether the respondent fears to be infected with COVID-19 in the future.

\section{Regions of Europe}

As explained above, we group the countries of the respondents into three groups based on geographical location, historical legacies and political culture: Eastern Europe (Bulgaria, Croatia, Czechia, Estonia, Hungary, Latvia, Lithuania, Poland, Romania, Slovakia, Slovenia), Western Europe (Austria, Belgium, Denmark, Finland, France, Germany, Ireland, Luxembourg, the Netherlands, Sweden) and Southern Europe (Cyprus, Greece, Italy, Malta, Portugal, Spain). The countries in Eastern Europe share a communist past and post-communist patterns of political competition and political culture. The countries in Southern Europe are characterized by lower levels of political trust than countries in the West of the continent and have relatively lower levels of economic development and administrative capacities.

\section{Empirical results}

\section{Levels of variables per region}

We begin the empirical analysis with a descriptive overview of the variables per region to demonstrate the differences in levels. Figure 3 shows the means per region (differences in country size are not taken into account). At the bottom of the figure, we can see the confirmation of the patterns already visible in the Figure 1: in Eastern Europe, levels of vaccine refusal and hesitancy are significantly higher (in fact, both are more than twice as high) than in the South and West of the continent. Beliefs that COVID-19 vaccines are safe and effective are also much lower in Eastern Europe, as is support for compulsory vaccination. However, people in Eastern Europe are actually more likely to report that they personally know someone who has been ill from COVID-19 (especially compared to Western Europe) and that they have been ill themselves. At the same time, Eastern Europeans are less likely to fear getting infected with COVID-19 and more likely to believe that they can avoid it without 
vaccination. When we consider the comparison between Southern and Western Europe, the most striking differences are with respect to fears to get COVID-19 and knowing someone who has been ill, both of which are much higher in the South. What we can conclude so far is that the much higher vaccine hesitancy and refusal in Eastern Europe might be related to beliefs about the effectiveness, safety and necessity of the vaccines, but not to lack of direct or indirect experience with COVID-19.

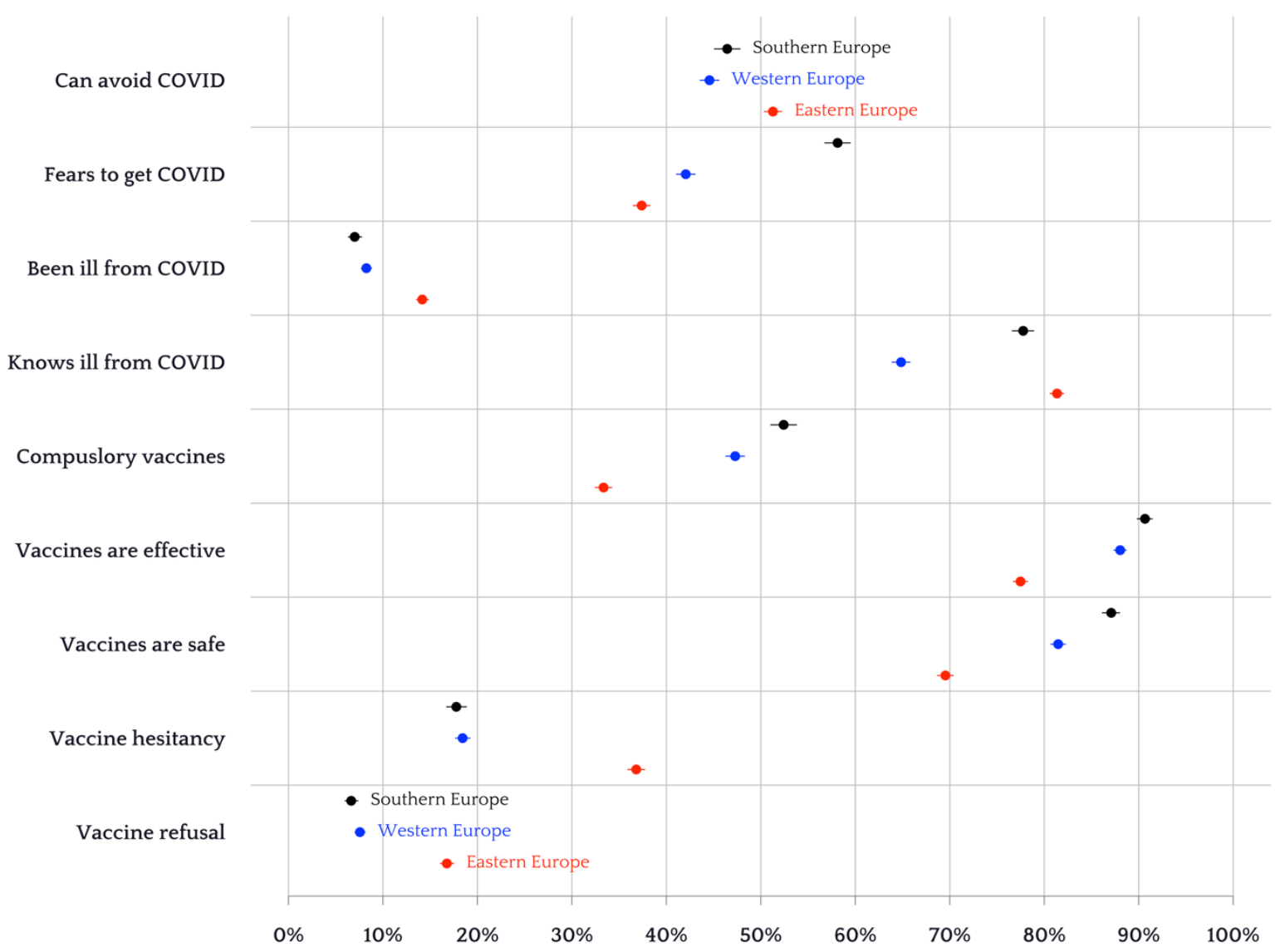

Figure 3. Experience and beliefs about COVID-19, beliefs and attitudes towards COVID-19 vaccines in three regions of the Europe (Eastern in red, Western in blue, Southern in black. Point estimates of the proportions in the population and 95\% confidence intervals (based on the Wilson method). Data: Flash Eurobarometer 494, May 2021.

Since beliefs about vaccines appear important, we examine which sources of information on COVID19 vaccines respondents consider to be trustworthy. Figure 4 shows the means per region. There are some striking differences, with East Europeans being much more likely to trust 'people around you (colleagues, friends and family)' and online social networks, rather than 'health professionals, doctors, nurses and pharmacists', national health authorities, regional and national governments. What is 
peculiar to the pattern in Southern Europe is that trust in the national and local governments is lower than in the West (but not as low as in the East), while trust in the EU and health professionals is higher. Importantly, trust in the traditional media (television, radio, newspapers) is lowest in Southern Europe.

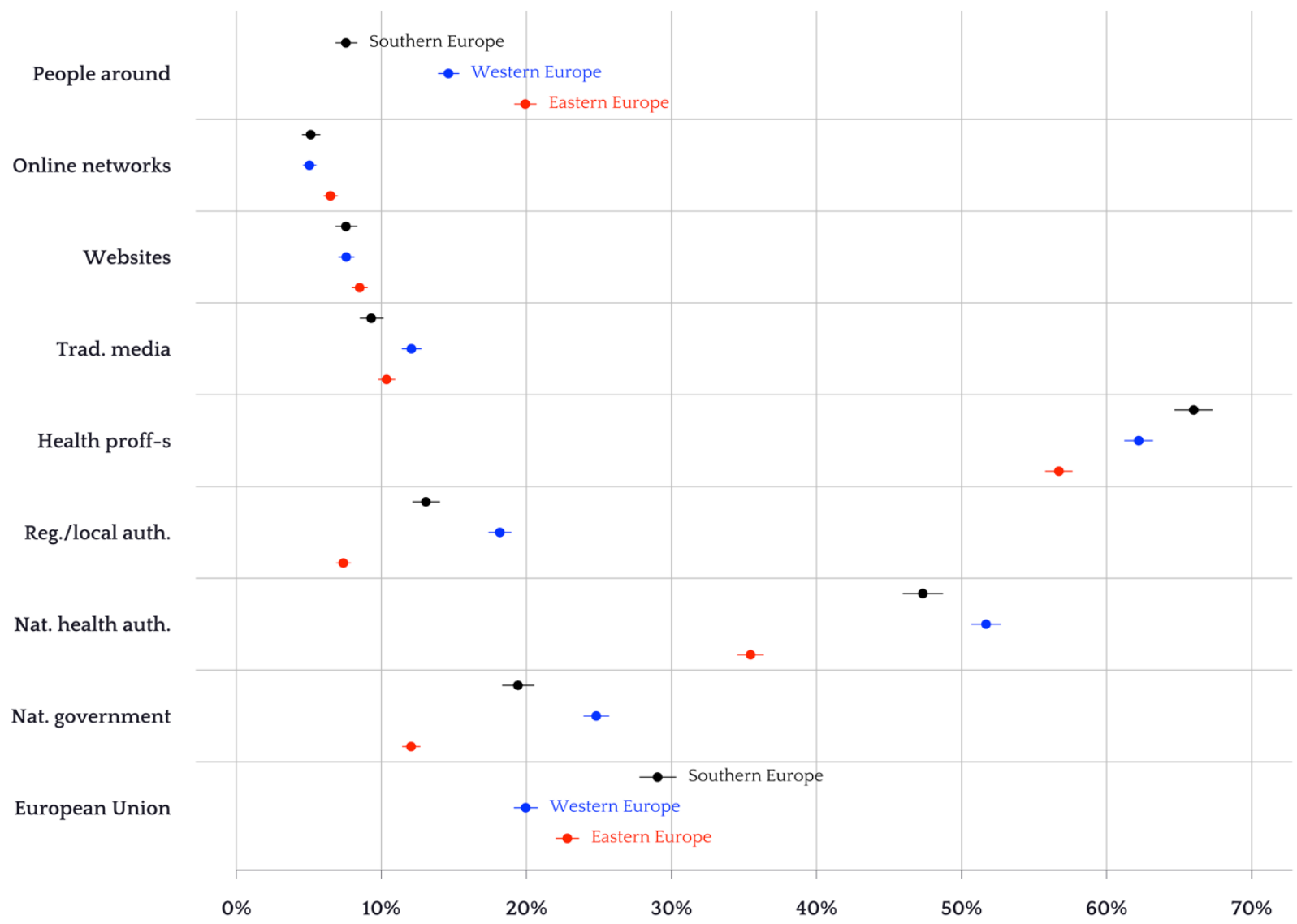

Figure 4. Trust in different 'sources of reliable information about COVID-19 vaccines' in three regions of the Europe (Eastern in red, Western in blue, Southern in black. Point estimates of the proportions in the population and $95 \%$ confidence intervals (based on the Wilson method). Data: Flash Eurobarometer 494, May 2021.

So far we considered only aggregate regional statistics, which are suggestive of possible explanations for the differences in vaccine attitudes we observe between regions, but to probe these explanations further, we move the analysis to the individual level.

Non-parametric effects of age and education 
First, we consider the effects of two demographic variables - age and education. We cannot assume that the effects of these variables are linear, so we use general additive models (Wood 2017), which allow for flexible forms of the effects. Figure 5 shows the probabilities of vaccine refusal (left) and hesitancy (right) per region. While greater age is altogether associated with lower levels of vaccine refusal and hesitancy, in Eastern Europe the effects are relatively flat until middle age (38 years or so), especially with regard to refusal. In Western Europe the probability of refusal actually increases between age 20 and 30, while in Southern Europe the decline of the probability of vaccine refusal with age is linear.
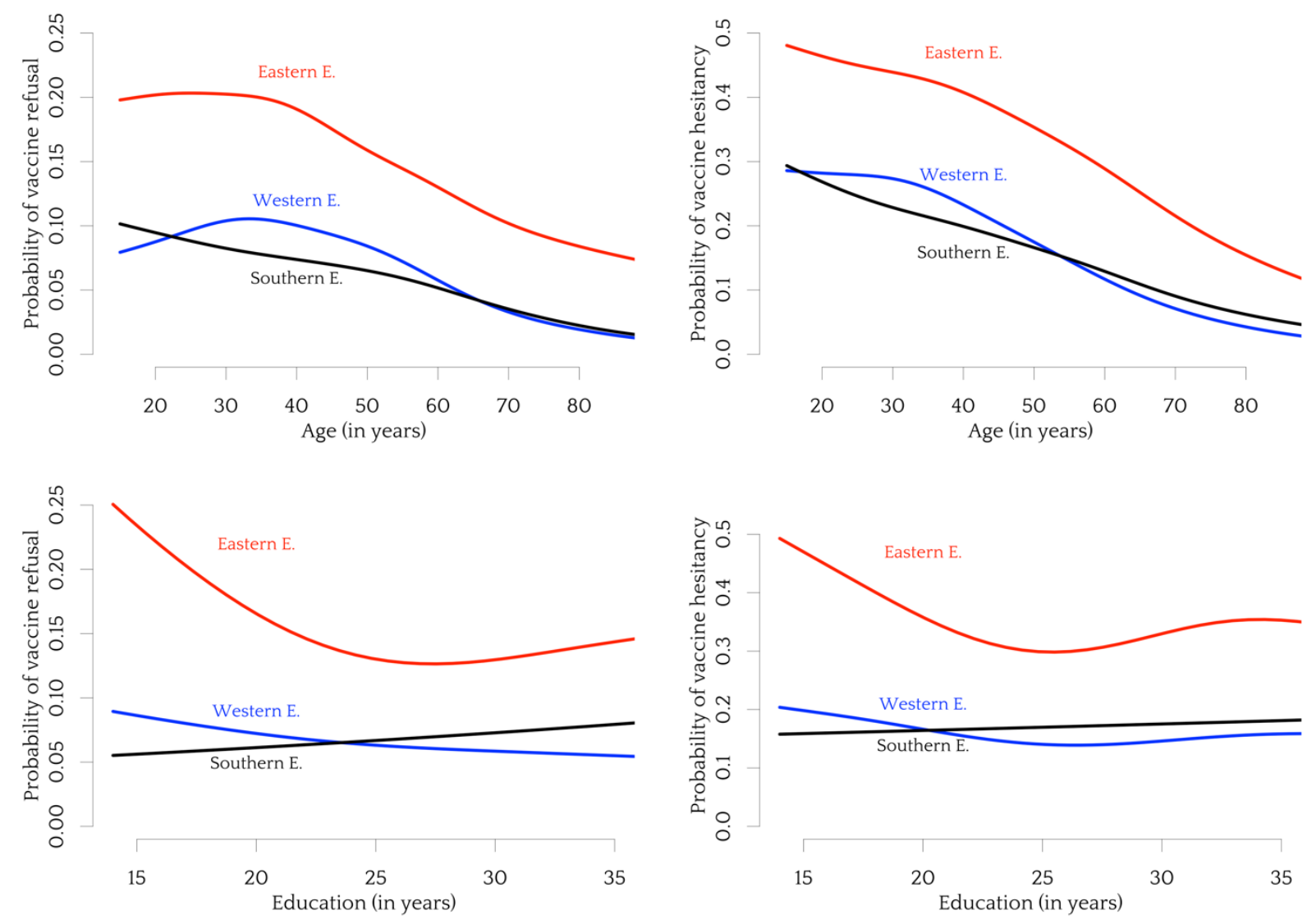

Figure 5. Non-linear effects of age (top row) and education (bottom row) on vaccine refusal (left column) and vaccine hesitancy (right column) in each of three regions of Europe. Semi-parametric smooth estimates of the effects based on generalized additive models (GAM).

The patterns differ across region even more when it comes to the effects of education. In Southern Europe, the probability of vaccine refusal is increasing with years spent in education and the probability of vaccine hesitancy is flat. In Western Europe the probability of vaccine refusal slightly 
declines and the probability of hesitancy drops until a point, but then stabilizes and even increases slightly. The pattern is similar in Eastern Europe as well, but starting from a much higher level for the lower educated. We conclude that the bivariate effects of age and education on vaccine hesitancy and refusal are altogether negative, but possibly non-linear and heterogenous across European regions.

\section{Effects of trust in different information sources, demographics and COVID-19 beliefs and experiences}

Next, we move to multivariate logistic regression models of vaccine hesitancy. Table 1 summarizes three models: the first one only features the information-based predictors, the second one adds demographic variables, and the third one adds beliefs about COVID-19 vaccines and experiences related to COVID-19. The reason to present the three models separately is to examine how the effects of the information-based variables change once we add the possibly-confounding demographic variables and when we add the possibly-mediating COVID-19 beliefs and experiences.

The models reported in Table 1 are estimated on the combined sample of respondents from all countries and regions in the EU (region fixed effects are included). In the next section we will explore how the effects differ per region using interaction effects. Table 1 shows the unexponentiated coefficients, so that negative values imply lower probability of being vaccine hesitant and positive values imply higher probability.

All the information-based variables have significant effects, with trust in health authorities, the $\mathrm{EU}$, and the medical profession having the biggest negative ones, and trust in Internet information, online social networks and 'people around' having positive effects (increasing the odds that someone is hesitant to vaccinate). Interestingly, the effect of trust in 'people around' (as a reliable source of vaccine information) is greatly reduced in size when we add the demographic predictors and turns insignificant when we add the COVID-19 vaccine beliefs. This implies that age and education confound the positive effect of trust in 'people around' on vaccine hesitancy and that, net of beliefs in the safety and efficacy of vaccines, the effect is undistinguishable from zero. In the presence of the demographic variables, the other information-based predictors do not diminish in importance, and some actually increase in size (e.g., trust in the EU). However, net of beliefs about vaccines and experiences with COVID-19, the effects of trust in doctors and in the media are halved in size.

From the demographic variables, the effects of age in the full sample is estimated to be negative (but see the previous section for the complex possibly non-linear nature of the effect, which is not captured in these models). The effect of education is negative only in the absence of the COVID-19 beliefs and experiences. 
Table 1. Multivariate logistic regression models of vaccine hesitancy in the EU.

\begin{tabular}{|c|c|c|c|c|c|c|}
\hline \multirow[b]{2}{*}{ Characteristic } & \multicolumn{2}{|c|}{ Model 1} & \multicolumn{2}{|c|}{ Model 2} & \multicolumn{2}{|c|}{ Model 3} \\
\hline & $\log (\mathrm{OR})$ & $\mathrm{p}$-value & $\log (\mathrm{OR})$ & $\mathrm{p}$-value & $\log (\mathrm{OR})$ & $\mathrm{p}$-value \\
\hline \multicolumn{7}{|l|}{ Region } \\
\hline Eastern Europe & - & & - & & - & \\
\hline Southern Europe & -0.81 & $<0.001$ & -0.83 & $<0.001$ & -0.50 & $<0.001$ \\
\hline Western Europe & -0.81 & $<0.001$ & -0.86 & $<0.001$ & -0.79 & $<0.001$ \\
\hline Trust.EU.info & -0.77 & $<0.001$ & -1.00 & $<0.001$ & -0.77 & $<0.001$ \\
\hline Trust.gov.info & -0.55 & $<0.001$ & -0.65 & $<0.001$ & -0.47 & $<0.001$ \\
\hline Trust.health.info & -1.10 & $<0.001$ & -1.10 & $<0.001$ & -0.78 & $<0.001$ \\
\hline Trust.local.info & -0.32 & $<0.001$ & -0.44 & $<0.001$ & -0.40 & $<0.001$ \\
\hline Trust.doctors.info & -0.86 & $<0.001$ & -0.82 & $<0.001$ & -0.46 & $<0.001$ \\
\hline Trust.media.info & -0.30 & $<0.001$ & -0.33 & $<0.001$ & -0.16 & 0.042 \\
\hline Trust.web.info & 0.28 & $<0.001$ & 0.30 & $<0.001$ & 0.23 & 0.002 \\
\hline Trust.networks.info & 0.45 & $<0.001$ & 0.50 & $<0.001$ & 0.42 & $<0.001$ \\
\hline Trust.people.info & 0.19 & $<0.001$ & 0.09 & 0.070 & 0.07 & 0.19 \\
\hline Age & & & -0.03 & $<0.001$ & -0.03 & $<0.001$ \\
\hline Education & & & -0.01 & 0.029 & 0.00 & 0.66 \\
\hline Sex [male] & & & -0.25 & $<0.001$ & -0.27 & $<0.001$ \\
\hline Residence [city] & & & -0.11 & 0.004 & -0.08 & 0.077 \\
\hline
\end{tabular}

Occupation

\begin{tabular}{rrrrrr} 
employee & - & & - & \\
Manual worker & 0.57 & $<\mathbf{0 . 0 0 1}$ & 0.49 & $<\mathbf{0 . 0 0 1}$ \\
No activity & 0.31 & $<\mathbf{0 . 0 0 1}$ & 0.27 & $<\mathbf{0 . 0 0 1}$ \\
Self-employed & 0.27 & $<\mathbf{0 . 0 0 1}$ & 0.23 & $<\mathbf{0 . 0 0 1}$ \\
\hline
\end{tabular}




\begin{tabular}{|c|c|c|c|c|}
\hline \multirow[b]{2}{*}{ Characteristic } & Model 1 & Model 2 & \multicolumn{2}{|c|}{ Model 3} \\
\hline & $\log (\mathrm{OR}) \mathrm{p}$-value & $\log (\mathrm{OR}) \mathrm{p}$-value & $\log (\mathrm{OR})$ & $\mathrm{p}$-value \\
\hline Vaccines are safe & & & -1.10 & $<0.001$ \\
\hline Vaccines are effective & & & -1.00 & $<0.001$ \\
\hline Knows ill from COVID-19 & & & -0.24 & $<0.001$ \\
\hline Was ill from COVID-19 & & & 0.20 & 0.001 \\
\hline Fears infection & & & -1.00 & $<0.001$ \\
\hline
\end{tabular}

Males and city-dwellers are significantly less likely to be vaccine-hesitant and the effects are stable. Compared to employees, manual workers, respondents with no economic activities and the selfemployed are significantly more likely to be vaccine-hesitant as well.

Unsurprisingly, beliefs in the safety and efficacy of vaccines have large and significant negative associations with vaccine hesitancy, as does the fear of getting infected. The negative effect of knowing someone who has been ill from the disease is significant but smaller in size. Having been sick with COVID-19 is positively associated with being hesitant to get a vaccine, perhaps on the belief that the experience grants immunity. In the Supplementary material we present the same set of models estimated on vaccine refusal as the outcome variable, but altogether the results are very similar (Table A1).

Varying effects in the different regions of Europe

Next, we explore how the effects discussed above differ in Eastern, Western and Southern Europe. We report a version of Model 3 with interactions of all variables with region in the Supplementary material (Table A2), and we illustrate the effects in Figures 6 and 7, which plot the estimated coefficients and 95\% confidence intervals per region. Looking first at trust in different information sources, the effect of trust in the EU is significantly smaller in Western Europe than in Eastern Europe. The effect of trust in the Internet is significantly higher in Southern Europe. The effect of trust in online social networks is smaller and the effect of trust in people is bigger in Western Europe than in the East. 


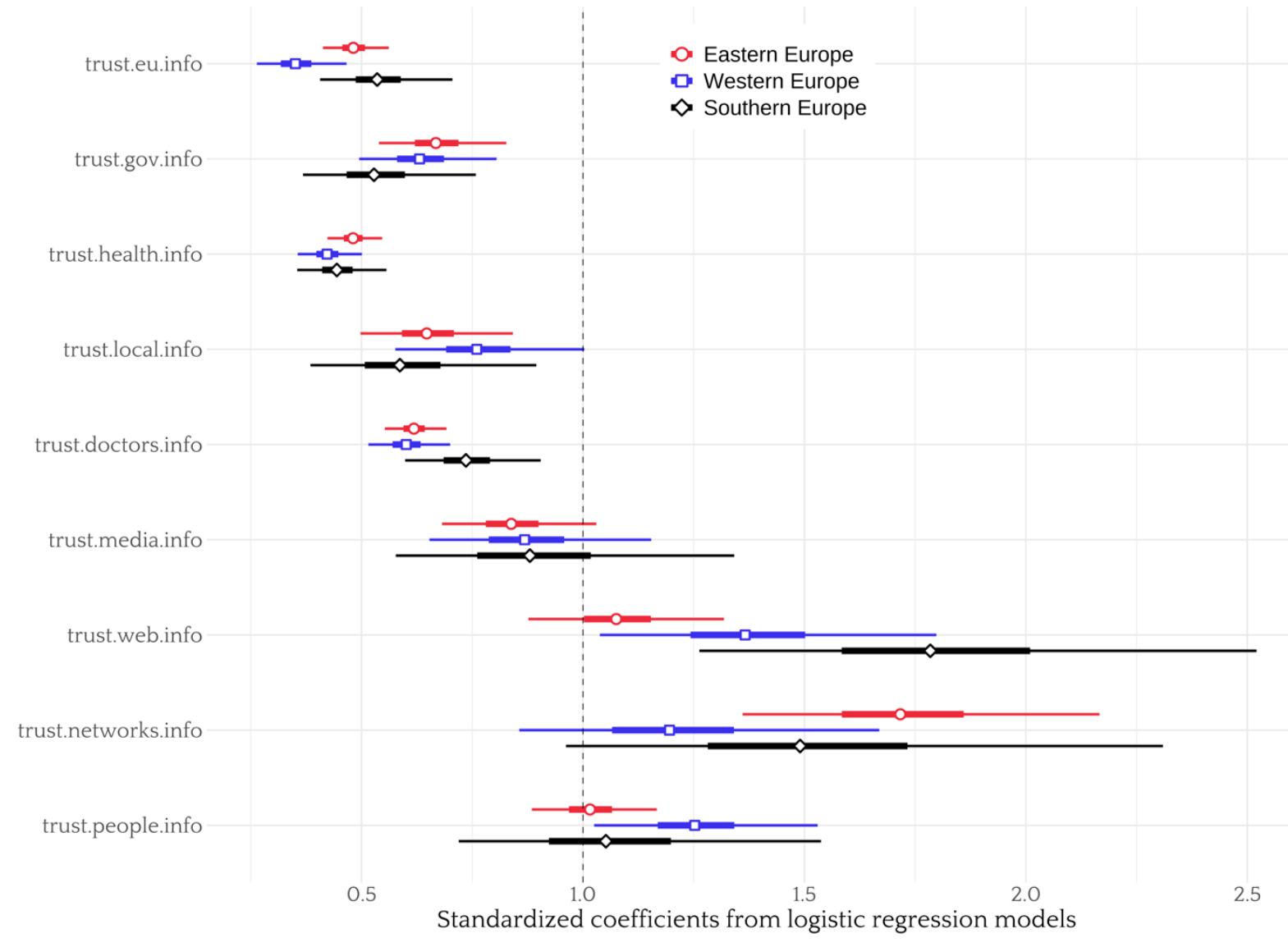

Figure 6. Effects of trust in different 'sources of reliable information about COVID-19 vaccines' on vaccine hesitancy in three regions of the Europe (Eastern in red, Western in blue, Southern in black. Standardized and exponentiated coefficients from Model A1 in Table A1 in the Supplementary Material, with $50 \%$ and $95 \%$ confidence intervals.

The effects of some demographic predictors also differ per region. The effects of age and city are smaller in Western Europe, while the effect education is bigger. The effect of being in the 'manual workers' category is much smaller, while the effect of belief in vaccine effectiveness is significantly bigger. Despite the presence of significant interactions, however, overall the variance explained by the models does not increase very much. That is, the interactions add little to the explanatory power of the models. This implies that differently effects of the variables included in the regressions are not responsible to a great extent for the observed differences in vaccine hesitancy in Eastern, Southern and Western Europe. The results are very similar with respect to vaccine refusal (also reported in Table A1, Model A2).

Reasons for vaccination 
The public opinion survey also includes questions about the reasons respondents opted to vaccinate or expressed hesitancy or refusal to do so. The usefulness of this data, however, is limited by the fact that different sets of reasons were provided to vaccine-approving and to vaccine-hesitant people. Therefore, we cannot know the overall popularity of different reasons in the total populations or to compare the appeal of different reasons between people with different opinions on vaccination. Nevertheless, we can compare the popularity of different reasons among the subsets of vaccineapproving and vaccine-hesitant respondents across the three European regions.

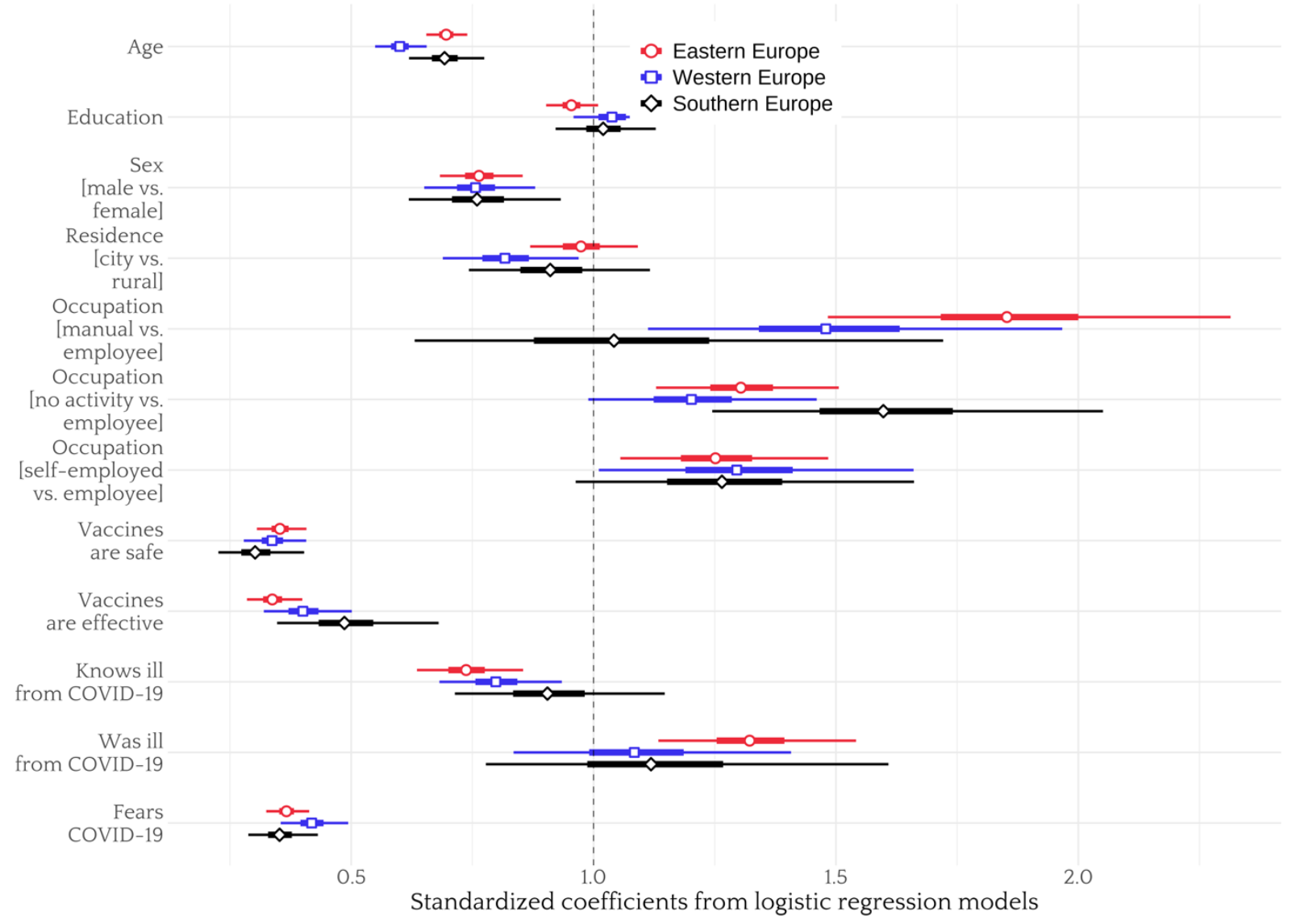

Figure 7. Effects of demographic variables and COVID-19-related beliefs and experiences on vaccine hesitancy in three regions of the Europe (Eastern in red, Western in blue, Southern in black. Standardized and exponentiated coefficients from Model A1 in Table A1 in the Supplementary Material, with $50 \%$ and $95 \%$ confidence intervals.

Figures A1 and A2 in the Supplementary material plot the means of agreement with different reasons per region. When it comes to vaccine hesitancy, there are not too many big differences in the popularity of different reasons. However, being against vaccines in general is much more common 
argument among the vaccine hesitant in Eastern Europe than in the West and the South. The most popular argument in Southern Europe is worry about side effects and that the vaccines have not been properly tested yet. Overall, Western European vaccine-hesitant respondents endorse the least all the possible reasons given.

Examining the reasons for vaccination, Southern European vaccine-approving people endorse to the greatest extent all the different possible reasons. For Western Europeans, the appeal of vaccines enabling travel and work is the weakest. Even though the arguments that vaccines will end the pandemic and will protect others are most popular in Eastern Europe compared to other arguments, their level of support is still significantly lower than in Western and Southern Europe. To remind, these differences are of limited use in explaining different levels of vaccine hesitancy in Europe, since only vaccine-accepting people were presented with reasons for vaccination and only vaccine-hesitant people were presented with reasons against (and because respondents could choose to endorse as many reasons as they want). But the relative popularity of different arguments across regions is still suggestive of the motivation of people to vaccinate or not.

\section{Mediation analysis}

The analyses above are useful for discovering significant associations between demographic, information-based and other variables with vaccine hesitancy and exploring the reasons for (non)vaccination, but they are not sufficient to identify causal effects of these variables as such, partly for the reason that the models do not consider the causal ordering of the variables included. While the observational and cross-sectional nature of the data preclude making valid causal inference without very strong assumptions, we can estimate a structural model of vaccine hesitancy that can provide estimates of direct, indirect and total effects of different variables. In particular, we propose a 2-step sequential mediation model, in which demographic variables (age and education) affect the likelihood to trust the Internet as a source of information on COVID-19 vaccines, which in its turn affects beliefs in the safety of the vaccines, which in their turn affect vaccine hesitancy. In addition, age and education affect directly beliefs about vaccine safety and vaccine hesitancy, and trust in the Internet affects directly vaccine hesitancy as well.

We estimate the mediation model sketched above using the lavaan package for $R$. The results are summarized in Figure 8, which shows the path coefficients for the direct effects and the estimates of the indirect effects and the total effects in the box. According to the model, the total effect of age on vaccine hesitance is negative, and most of the effect is exercised directly. The indirect effects of 
age via vaccine beliefs and via trust in the Internet are significant, but much smaller in size and importance. The total effect of education is also estimated to be negative and is mostly exercised directly. In fact, there does not seem to be a significant effect of education on trust in the Internet as a source of information on COVID-19 vaccines, which precludes the two-step mediation effect. The direct effect of education on belief in the safety of vaccines is large, positive and significant. The effect of trust in the Internet on vaccine hesitancy is positive, large and significant both directly and indirectly via the belief that vaccines are safe.

In the Supplementary information we present this mediation model estimated in each region in Europe to explore how the patterns differ. There are no major differences between Eastern and Western Europe, but the model for Southern Europe has all direct and indirect effects of education as insignificant. The total effect of trust in the Internet is smallest in Western Europe and greatest in Eastern Europe.

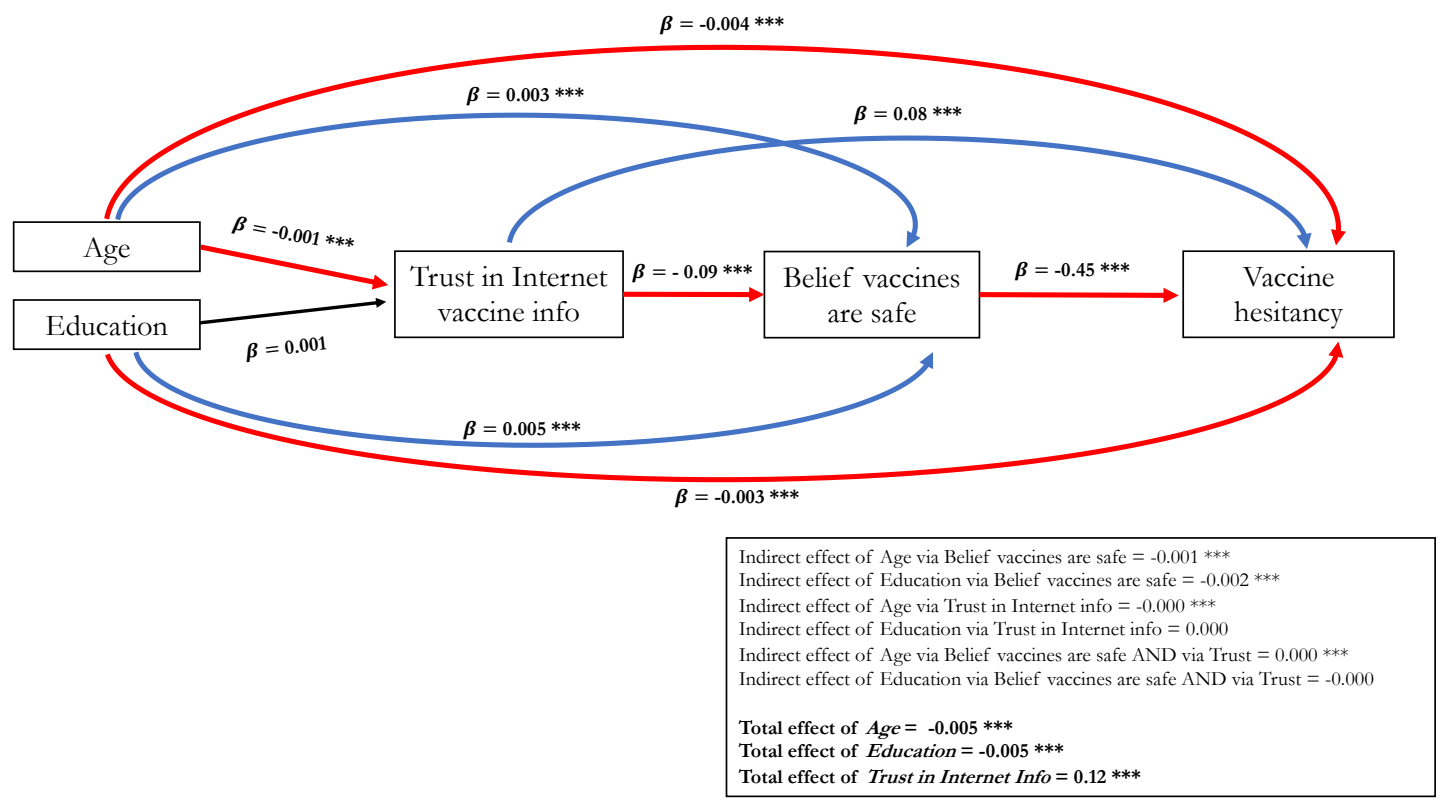

Figure 8. Results from mediation analysis of vaccine hesitancy (two-step sequential mediation model) estimated with the lavaan package for R. Logit links are specified for the three equations, since the outcome variables are all binary. Significant positive links are in blue and negative ones are in red; nonsignificant links are in black. Standardized coefficients are reported (standard errors are not printed); stars indicate levels of statistical significance: $* * *<0.001 ; * *<0.01, *<0.05$ 


\section{Conclusion}

This article used comparative data from 27 European countries to examine the individual-level predictors of COVID-19 vaccine hesitancy and refusal at an important point in time - May 2021 when mass vaccination campaigns were in their early stages. In line with existing literature, the analyses showed that several demographic factors have significant associations on vaccine hesitancy and refusal. Age exhibited negative effects, but ones that are possibly non-linear. The effect of education is also negative, but smaller and heterogenous across European regions. Males, city dwellers and employees were consistently less likely to be vaccine hesitant. The mediation analyses also found that the effects of age and education are both and indirect, via trust in different sources of information on COVID-19 vaccines and via beliefs in the safety of vaccines.

The article reported strong evidence that the types of information sources that people trust has substantively big and statistically significant associations with vaccine hesitancy and refusal. People who tend to trust EU, national and local governments, as well as medical professionals and health authorities are much less likely to be vaccine hesitant, while people how tend to trust the Internet, online social networks and 'people around' show the opposite tendency. These inferences are consistent with existing literature about trust and the influence of non-traditional media sources on health-related beliefs and behaviors. But it still remains unclear to what extent the effects of trust are causal in a strict sense rather than being confounded by more general socio-political orientations (e.g. trust in government as such) and patterns of media consumption. The mediation analyses reported in this article suggest that trust in the Internet as a source of information on COVID-19 vaccines has both a direct effect, as well as an indirect effect via belief in the safety of vaccines.

Beliefs in the safety and effectiveness of vaccines had significant predictive power for vaccine hesitancy, but for these variables concerns about endogeneity loom even larger when we consider whether they have causal effects as such. Beliefs and experiences related to COVID-19 had significant predictive power as well, with people fearing infection and knowing people who have been sick from the diseases less likely to report vaccine hesitancy and refusal. But people who had had the disease themselves were more likely to be vaccine hesitant (but not refuse vaccines altogether).

A major motivation of this study was to shed light on the reasons why vaccines hesitancy and refusal were much higher in Eastern rather than in Southern and Western Europe. The analyses showed some evidence for differential effects of the demographic and trust-related variables. For example, the effect of education is non-existent in Southern Europe and the effect of age is flatter under middle age in Eastern Europe. But, altogether, it is differences in levels of the variables across 
regions that can account for the differences in vaccine hesitancy and refusal than differential effects of these variables. The reasons endorsed for or against vaccination also do not show major differences across European regions. Therefore, we have to conclude that the structures explaining vaccine hesitancy do not seem to differ much across regions. Rather, it is the much higher prevalence of variables such as distrust of national governments and medical processionals as source of relevant information in Eastern Europe that are relevant.

The importance of vaccine hesitancy as a constraint in the fight against the corona virus pandemic was demonstrated already in the introductory chapter by reference to its very high correlation with actual vaccination rates across Europe. Since the autumn of 2021 many of the European countries increased by the incentives for vaccination and the pressure on the vaccinehesitant population by various policy measures. But the vaccine-related attitudes studied in this paper remain relevant, as new challenges arise, such as the need for booster COVID-19 vaccination shots and the vaccination of children.

Some of the practical implications of this work echo recommendations from the existing literature. The importance of trust in different media sources and beliefs about the safety and efficacy of the vaccines calls both for public information campaigns that explain how vaccines work and are developed, as well as for more general measures clarifying why certain sources of vaccine and medical information are most trustworthy than others (Paladini et al. 2021; Obregon et al. 2020; Marco-Franco et al. 2021). But the significant heterogeneity in relevant attitudes in beliefs across Europe means that interventions need to take into account the local context (cf. Salomoni et al. 2021).

To be on firmer ground when endorsing recommendations about addressing vaccine hesitancy, future research should probe further the causal nature of the associations explored in this article. The observational nature of the evidence presented here precludes strong causal claims, even if the multivariate regressions and the mediation analyses in particular addressed some concerns about confounders and causal ordering. Another important limitation of this research is that the 27 European states were grouped in three clusters, defined on the basis of shared historical legacies (communist rule in particular) and broad socio-political similarities. Different ways to address the heterogeneity of vaccine-related attitudes across countries are possible, including defining different clusters (for example, separating Northern and South-Eastern countries from Western and Eastern Europe, respectively). Finally, future research should strive to link the variables studied in this article to more general social and political attitudes, which - despite its theoretical importance - has not been possible to be done in this study due to the limitations of the public opinion survey used as a data 
source. A more comprehensive understanding of vaccine hesitancy needs to consider the broader socio-political environment in which European citizens process relevant information and form attitudes and beliefs.

\section{References}

Alvarez-Galvez, Javier, Jose A Salinas-Perez, Ilaria Montagni, and Luis Salvador-Carulla. 2020. "The Persistence of Digital Divides in the Use of Health Information: A Comparative Study in 28 European Countries." International Journal of Public Health 65 (3): 325-33.

Anastasiou, Olympia E, and Dörte Heger. 2021. "Understanding the Influence of Individual and Systemic Factors on Vaccination Take-Up in European Citizens Aged 55 or Older." Vaccines 9 (2).

Bergmann, M, T Hannemann, A Bethmann, and A T Schumacher. 2021. "Determinants of SARSCoV-2 Vaccinations in the 50+ Population."

Costa-Font, J, J Garcia-Hombrados, and A Nicińska. 2021. "The Institutional Origins of Vaccines Distrust: Evidence from Former-Communist Countries."

Crawshaw, Jacob, Kristin Konnyu, Gisell Castillo, Zack van Allen, J M Grimshaw, and J Presseau. 2021. "Factors Affecting COVID-19 Vaccination Acceptance and Uptake among the General Public: A Living Behavioural Science Evidence Synthesis (v4, July 31st, 2021).” Ottawa: Ottawa Hospital Research Institute.

El-Elimat, Tamam, Mahmoud M AbuAlSamen, Basima A Almomani, Nour A Al-Sawalha, and Feras Q Alali. 2021. "Acceptance and Attitudes toward COVID-19 Vaccines: A Cross-Sectional Study from Jordan.” PLOS ONE 16 (4): e0250555.

Fournet, N, L Mollema, W L Ruijs, I A Harmsen, F Keck, J Y Durand, M P Cunha, et al. 2018. "Under-Vaccinated Groups in Europe and Their Beliefs, Attitudes and Reasons for NonVaccination; Two Systematic Reviews.” BMC Public Health 18 (1): 196.

Green, Jon, J Druckman, M Baum, David Lazer, Katherine Ognyanova, Matthew D Simonson, Jennifer Lin, Mauricio Santillana, and Roy H Perlis. 2021. "Using General Messages to Persuade on a Politicized Scientific Issue." Working Paper.

Kate, Josje Ten, Willem De Koster, and Jeroen Van der Waal. 2021. “Following Your Gut' or 'Questioning the Scientific Evidence': Understanding Vaccine Skepticism among MoreEducated Dutch Parents." Journal of Health and Social Behavior 62 (1): 85-99.

Lazarus, Jeffrey V, Katarzyna Wyka, Lauren Rauh, Kenneth Rabin, Scott Ratzan, Lawrence O Gostin, Heidi J Larson, and Ayman El-Mohandes. 2020. "Hesitant or Not? The Association of Age, Gender, and Education with Potential Acceptance of a COVID-19 Vaccine: A Country-Level Analysis." Journal of Health Communication 25 (10): 799-807.

Lewis, Andrew, and Raymond Duch. 2021. "Gender Differences in Perceived Risk of COVID-19." Social Science Quarterly 102 (5): 2124-33.

Lindholt, Marie Fly, Frederik Jørgensen, Alexander Bor, and Michael Bang Petersen. 2021. "Public Acceptance of COVID-19 Vaccines: Cross-National Evidence on Levels and Individual-Level Predictors Using Observational Data.” BMJ Open 11 (6): e048172.

Marco-Franco, Julio E, Pedro Pita-Barros, David Vivas-Orts, Silvia González-de-Julián, and David Vivas-Consuelo. 2021. "COVID-19, Fake News, and Vaccines: Should Regulation Be Implemented?" International Journal of Environmental Research and Public Health .

Neumann-Böhme, Sebastian, Nirosha Elsem Varghese, Iryna Sabat, Pedro Pita Barros, Werner Brouwer, Job van Exel, Jonas Schreyögg, and Tom Stargardt. 2020. “Once We Have It, Will We 
Use It? A European Survey on Willingness to Be Vaccinated against COVID-19.” The European Journal of Health Economics 21 (7): 977-82.

Obregon, Rafael, Mario Mosquera, Sergiu Tomsa, and Ketan Chitnis. 2020. "Vaccine Hesitancy and Demand for Immunization in Eastern Europe and Central Asia: Implications for the Region and Beyond." Journal of Health Communication 25 (10): 808-15.

Paladini, A, L Regazzi, C Castagna, M Sapienza, A Rosano, W Ricciardi, and C Cadeddu. 2021. "Public Opinion on Vaccines: The Role of the Scientific Community in Italy." European Journal of Public Health 31 (Supplement_3): ckab165.469.

Paul, Elise, Andrew Steptoe, and Daisy Fancourt. 2021. "Attitudes towards Vaccines and Intention to Vaccinate against COVID-19: Implications for Public Health Communications." The Lancet Regional Health - Europe 1 (February).

Petravić, Luka, Rok Arh, Tina Gabrovec, Lucija Jazbec, Nika Rupčić, Nina Starešinič, Lea Zorman, et al. 2021. "Factors Affecting Attitudes towards COVID-19 Vaccination: An Online Survey in Slovenia." Vaccines .

Pfattheicher, Stefan, Michael Bang Petersen, and Robert Böhm. 2021. "Information about Herd Immunity through Vaccination and Empathy Promote COVID-19 Vaccination Intentions." Health Psychology, No Pagination Specified-No Pagination Specified.

Phillips, Rhiannon, David Gillespie, Britt Hallingberg, Jennifer Evans, Khadijeh Taiyari, Anna Torrens-Burton, Rebecca Cannings-John, Denitza Williams, Elizabeth Sheils, and Pauline Ashfield-Watt. 2021. "Perceived Threat of COVID-19, Attitudes towards Vaccination, and Vaccine Hesitancy: A Prospective Longitudinal Study in the UK."

Rhodes, Matthew E, Beth Sundstrom, Emily Ritter, Brooke W McKeever, and Robert McKeever. 2020. "Preparing for A COVID-19 Vaccine: A Mixed Methods Study of Vaccine Hesitant Parents." Journal of Health Communication 25 (10): 831-37.

Romer, Daniel, and Kathleen Hall Jamieson. 2021. "Conspiratorial Thinking, Selective Exposure to Conservative Media, and Response to COVID-19 in the US." Social Science \& Medicine 291: 114480.

Sallam, Malik. 2021. "COVID-19 Vaccine Hesitancy Worldwide: A Concise Systematic Review of Vaccine Acceptance Rates." Vaccines .

Salomoni, Maria G, Zeno Di Valerio, Elisa Gabrielli, Marco Montalti, Dario Tedesco, Federica Guaraldi, and Davide Gori. 2021. "Hesitant or Not Hesitant? A Systematic Review on Global COVID-19 Vaccine Acceptance in Different Populations." V accines .

Sowa, Paweł, Łukasz Kiszkiel, Piotr P Laskowski, Maciej Alimowski, Łukasz Szczerbiński, Marlena Paniczko, Anna Moniuszko-Malinowska, and Karol Kamiński. 2021. "COVID-19 Vaccine Hesitancy in Poland-Multifactorial Impact Trajectories." V accines .

Stroope, Samuel, Rhiannon A Kroeger, Courtney E Williams, and Joseph O Baker. 2021. "Sociodemographic Correlates of Vaccine Hesitancy in the United States and the Mediating Role of Beliefs about Governmental Conspiracies.” Social Science Quarterly 102 (6): 2472-81.

Sturgis, Patrick, Ian Brunton-Smith, and Jonathan Jackson. 2021. "Trust in Science, Social Consensus and Vaccine Confidence." Nature Human Behaviour 5 (11): 1528-34.

Vosheva, N A, N N Kamynina, E O Korotkova, and D V Voshev. 2021. "[The comparative analysis of population attitude to vaccination against COVID-19 infection in foreign countries and in Russia]." Problemy sotsial'noi gigieny, zdravookhraneniia $i$ istorii meditsiny 29 (2): 220-26.

Waszak, Przemyslaw M, Wioleta Kasprzycka-Waszak, and Alicja Kubanek. 2018. "The Spread of Medical Fake News in Social Media - The Pilot Quantitative Study." Health Policy and Technology 7 (2): 115-18.

Wawrzuta, Dominik, Mariusz Jaworski, Joanna Gotlib, and Mariusz Panczyk. 2021. "Social Media Sharing of Articles About Measles in a European Context: Text Analysis Study." J Med Internet 
Res 23 (11): e30150.

Wilson, Steven Lloyd, and Charles Wiysonge. 2020. "Social Media and Vaccine Hesitancy." BMJ Global Health 5 (10): e004206.

Wood, Simon N. 2017. Generalized Additive Models: An Introduction with R. CRC press.

Yaqub, Ohid, Sophie Castle-Clarke, Nick Sevdalis, and Joanna Chataway. 2014. "Attitudes to Vaccination: A Critical Review." Social Science \& Medicine 112: 1-11.

Żuk, Piotr, Paweł Żuk, and Justyna Lisiewicz-Jakubaszko. 2019. "The Anti-Vaccine Movement in Poland: The Socio-Cultural Conditions of the Opposition to Vaccination and Threats to Public Health." Vaccine 37 (11): 1491-94. 


\section{Supplementary materials}

Reasons for vaccination and vaccine hesitancy

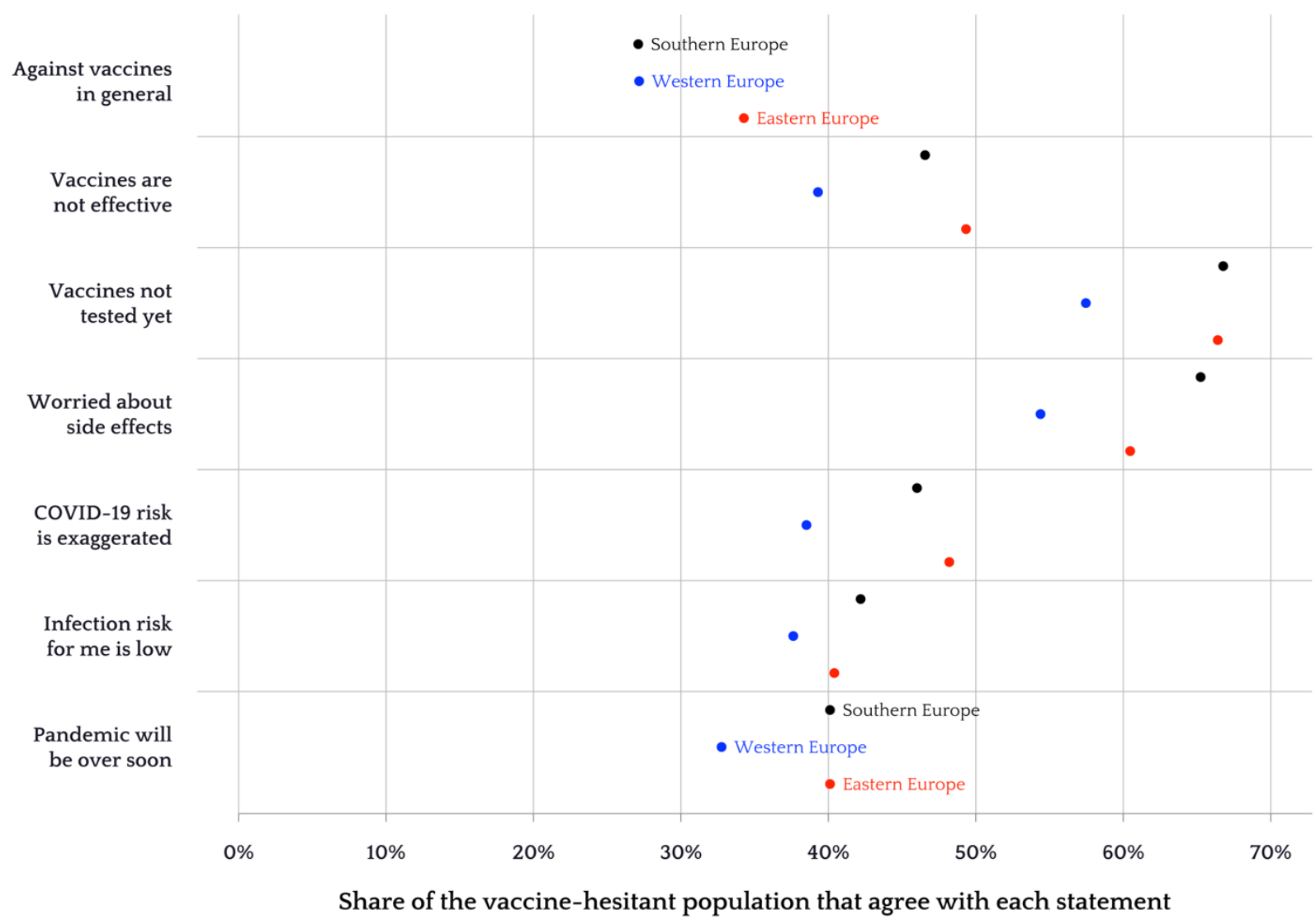

Figure A1. Share of the vaccine-hesitant population in Eastern, Wester and Southern Europe that agree with each reason for non-vaccinating. Data: Flash Eurobarometer 494, May 2021. 


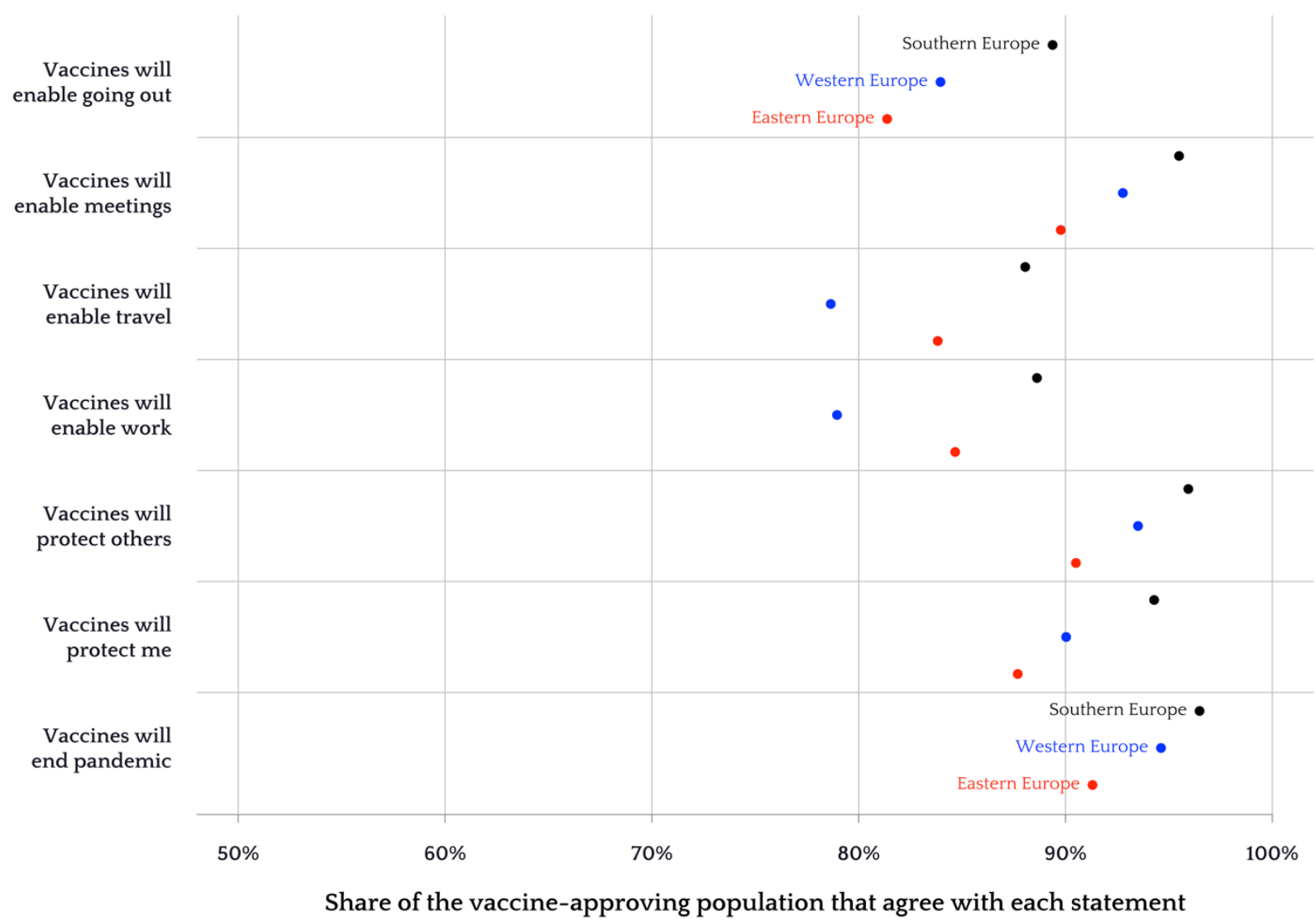

Figure A2. Share of the vaccine-approving population in Eastern, Wester and Southern Europe that agree with each reason for vaccinating. Data: Flash Eurobarometer 494, May 2021. 
Multivariate models of vaccine refusal

Table A1. Logistic regression models of vaccine refusal

\begin{tabular}{|c|c|c|c|c|c|c|}
\hline \multirow[b]{2}{*}{ Characteristic } & \multicolumn{2}{|c|}{ Model A1 } & \multicolumn{2}{|c|}{ Model A2 } & \multicolumn{2}{|c|}{ Model A3 } \\
\hline & $\log (\mathrm{OR})$ & p-val. & $\log (\mathrm{OR})$ & p-val. & $\log (\mathrm{OR})$ & p-val. \\
\hline \multicolumn{7}{|l|}{ Region } \\
\hline Eastern Europe & - & & - & & - & \\
\hline Southern Europe & -0.79 & $<0.001$ & -0.81 & $<0.001$ & -0.42 & $<0.001$ \\
\hline Western Europe & -0.72 & $<0.001$ & -0.70 & $<0.001$ & -0.55 & $<0.001$ \\
\hline Trust.EU.info & -1.2 & $<0.001$ & -1.4 & $<0.001$ & -1.1 & $<0.001$ \\
\hline Trust.gov.info & -0.80 & $<0.001$ & -0.79 & $<0.001$ & -0.49 & $<0.001$ \\
\hline Trust.health.info & -1.5 & $<0.001$ & -1.5 & $<0.001$ & -1.1 & $<0.001$ \\
\hline Trust.local.info & -0.51 & $<0.001$ & -0.60 & $<0.001$ & -0.45 & 0.001 \\
\hline Trust.doctors.info & -1.1 & $<0.001$ & -1.1 & $<0.001$ & -0.74 & $<0.001$ \\
\hline Trust.media.info & -0.49 & $<0.001$ & -0.54 & $<0.001$ & -0.30 & 0.010 \\
\hline Trust.web.info & 0.27 & $<0.001$ & 0.31 & $<0.001$ & 0.27 & 0.004 \\
\hline Trust.networks.info & 0.48 & $<0.001$ & 0.54 & $<0.001$ & 0.53 & $<0.001$ \\
\hline Trust.people.info & -0.17 & 0.002 & -0.28 & $<0.001$ & -0.30 & $<0.001$ \\
\hline Age & & & -0.02 & $<0.001$ & -0.02 & $<0.001$ \\
\hline Education & & & -0.01 & 0.12 & 0.00 & 0.76 \\
\hline Sex [male] & & & -0.09 & 0.080 & -0.09 & 0.085 \\
\hline Residence [city] & & & -0.11 & 0.033 & -0.09 & 0.12 \\
\hline \multicolumn{7}{|l|}{ Occupation } \\
\hline Employee & & & - & & - & \\
\hline Manual worker & & & 0.21 & 0.028 & 0.09 & 0.41 \\
\hline No activity & & & 0.26 & $<0.001$ & 0.21 & 0.002 \\
\hline
\end{tabular}




\begin{tabular}{|c|c|c|c|c|c|c|}
\hline \multirow[b]{2}{*}{ Characteristic } & \multicolumn{2}{|c|}{ Model A1 } & \multicolumn{2}{|c|}{ Model A2 } & \multicolumn{2}{|c|}{ Model A3 } \\
\hline & $\log (\mathrm{OR})$ & p-val. & $\log (\mathrm{OR})$ & p-val. & $\log (\mathrm{OR})$ & p-val. \\
\hline self-employed & & & 0.29 & $<0.001$ & 0.24 & 0.003 \\
\hline Vaccines are safe & & & & & -0.89 & $<0.001$ \\
\hline Vaccines are effective & & & & & -0.74 & $<0.001$ \\
\hline Knows ill from COVID-19 & & & & & -0.07 & 0.25 \\
\hline Was ill from COVID-19 & & & & & 0.02 & 0.81 \\
\hline Fears infection & & & & & -1.4 & $<0.001$ \\
\hline
\end{tabular}


Multivariate models of vaccine hesitancy and refusal with region interactions

Table A2. Logistic regression models

\begin{tabular}{|c|c|c|c|c|}
\hline \multirow[b]{2}{*}{ Characteristic } & \multicolumn{2}{|c|}{$\begin{array}{c}\text { Model } 4 \\
\text { (hesitancy) }\end{array}$} & \multicolumn{2}{|c|}{$\begin{array}{c}\text { Model 5 } \\
\text { (refusal) }\end{array}$} \\
\hline & $\log (\mathrm{OR})$ & $\mathrm{p}$-value & $\log (\mathrm{OR})$ & $\mathrm{p}$-value \\
\hline \multicolumn{5}{|l|}{ Region } \\
\hline Eastern Europe & - & & - & \\
\hline Southern Europe & -1.30 & 0.002 & -0.69 & 0.21 \\
\hline Western Europe & -0.91 & 0.003 & -0.79 & 0.032 \\
\hline Trust.EU.info & -0.73 & $<0.001$ & -1.00 & $<0.001$ \\
\hline Trust.gov.info & -0.40 & $<0.001$ & -0.34 & 0.037 \\
\hline Trust.health.info & -0.73 & $<0.001$ & -1.00 & $<0.001$ \\
\hline Trust.local.info & -0.44 & 0.001 & -0.68 & 0.001 \\
\hline Trust.doctors.info & -0.48 & $<0.001$ & -0.73 & $<0.001$ \\
\hline Trust.media.info & -0.18 & 0.094 & -0.16 & 0.25 \\
\hline Trust.web.info & 0.07 & 0.49 & 0.28 & 0.021 \\
\hline Trust.networks.info & 0.54 & $<0.001$ & 0.60 & $<0.001$ \\
\hline Trust.people.info & 0.02 & 0.82 & -0.33 & $<0.001$ \\
\hline Age & -0.02 & $<0.001$ & -0.02 & $<0.001$ \\
\hline Education & -0.01 & 0.10 & -0.01 & 0.16 \\
\hline Sex [male] & -0.27 & $<0.001$ & -0.13 & 0.065 \\
\hline Residence [city] & -0.03 & 0.65 & -0.11 & 0.14 \\
\hline \multicolumn{5}{|l|}{ Occupation } \\
\hline employee & - & & - & \\
\hline Manual worker & 0.62 & $<0.001$ & 0.17 & 0.19 \\
\hline
\end{tabular}




\begin{tabular}{|c|c|c|c|c|}
\hline \multirow[b]{2}{*}{ Characteristic } & \multicolumn{2}{|c|}{$\begin{array}{c}\text { Model } 4 \\
\text { (hesitancy) }\end{array}$} & \multicolumn{2}{|c|}{$\begin{array}{c}\text { Model } 5 \\
\text { (refusal) }\end{array}$} \\
\hline & $\log (\mathrm{OR})$ & p-value & $\log (\mathrm{OR})$ & p-value \\
\hline No activity & 0.27 & $<0.001$ & 0.21 & 0.018 \\
\hline Self-employed & 0.22 & 0.010 & 0.09 & 0.37 \\
\hline Vaccines are safe & -1.0 & $<0.001$ & -0.85 & $<0.001$ \\
\hline Vaccines are effective & -1.1 & $<0.001$ & -0.70 & $<0.001$ \\
\hline Knows ill from COVID-19 & -0.31 & $<0.001$ & -0.03 & 0.70 \\
\hline Was ill from COVID-19 & 0.28 & $<0.001$ & -0.04 & 0.70 \\
\hline Fears infection & -1.0 & $<0.001$ & -1.4 & $<0.001$ \\
\hline Southern Europe * trust.EU.info & 0.11 & 0.51 & -0.27 & 0.39 \\
\hline Western Europe * trust.EU.info & -0.32 & 0.055 & -0.30 & 0.30 \\
\hline Southern Europe * trust.gov.info & -0.23 & 0.27 & -0.29 & 0.44 \\
\hline Western Europe * trust.gov.info & -0.06 & 0.73 & -0.23 & 0.38 \\
\hline Southern Europe * trust.health.info & -0.08 & 0.55 & -0.31 & 0.20 \\
\hline Western Europe * trust.health.info & -0.13 & 0.23 & -0.23 & 0.20 \\
\hline Southern Europe * trust.local.info & -0.10 & 0.70 & -0.20 & 0.67 \\
\hline Western Europe * trust.local.info & 0.16 & 0.41 & 0.65 & 0.032 \\
\hline Southern Europe * trust.doctors.info & 0.17 & 0.15 & -0.02 & 0.91 \\
\hline Western Europe * trust.doctors.info & -0.03 & 0.77 & -0.05 & 0.73 \\
\hline Southern Europe * trust.media.info & 0.05 & 0.84 & -0.48 & 0.27 \\
\hline Western Europe * trust.media.info & 0.04 & 0.84 & -0.36 & 0.19 \\
\hline Southern Europe * trust.web.info & 0.51 & 0.013 & 0.05 & 0.86 \\
\hline Western Europe * trust.web.info & 0.24 & 0.17 & -0.12 & 0.58 \\
\hline Southern Europe * trust.networks.info & -0.14 & 0.58 & -0.04 & 0.91 \\
\hline
\end{tabular}




\begin{tabular}{|c|c|c|c|c|}
\hline \multirow[b]{2}{*}{ Characteristic } & \multicolumn{2}{|c|}{$\begin{array}{c}\text { Model } 4 \\
\text { (hesitancy) }\end{array}$} & \multicolumn{2}{|c|}{$\begin{array}{c}\text { Model } 5 \\
\text { (refusal) }\end{array}$} \\
\hline & $\log (\mathrm{OR})$ & p-value & $\log (\mathrm{OR})$ & $\mathrm{p}$-value \\
\hline Western Europe * trust.networks.info & -0.36 & 0.081 & -0.25 & 0.33 \\
\hline Southern Europe * trust.people.info & 0.03 & 0.87 & -0.01 & 0.97 \\
\hline Western Europe * trust.people.info & 0.21 & 0.092 & 0.16 & 0.36 \\
\hline Southern Europe * Age & 0.00 & 0.91 & -0.01 & 0.29 \\
\hline Western Europe * Age & -0.01 & 0.032 & 0.00 & 0.72 \\
\hline Southern Europe * Education & 0.02 & 0.25 & 0.03 & 0.11 \\
\hline Western Europe * Education & 0.02 & 0.076 & 0.02 & 0.22 \\
\hline Southern Europe * Male & -0.01 & 0.96 & 0.18 & 0.31 \\
\hline Western Europe * Male & -0.01 & 0.92 & 0.05 & 0.72 \\
\hline Southern Europe * City & -0.07 & 0.57 & 0.07 & 0.70 \\
\hline Western Europe * City & -0.18 & 0.093 & 0.00 & 0.98 \\
\hline Southern Europe * manual & -0.58 & 0.040 & -1.3 & 0.014 \\
\hline Western Europe * manual & -0.23 & 0.22 & -0.06 & 0.81 \\
\hline Southern Europe * no activity & 0.20 & 0.17 & 0.33 & 0.12 \\
\hline Western Europe * no activity & -0.08 & 0.51 & -0.16 & 0.33 \\
\hline Southern Europe * self-employed & 0.01 & 0.95 & 0.42 & 0.062 \\
\hline Western Europe * self-employed & 0.03 & 0.82 & 0.31 & 0.12 \\
\hline Southern Europe * vaccines.safe & -0.16 & 0.34 & -0.09 & 0.68 \\
\hline Western Europe * vaccines.safe & -0.05 & 0.70 & -0.10 & 0.51 \\
\hline Southern Europe * vaccines.effective & 0.37 & 0.057 & -0.12 & 0.62 \\
\hline Western Europe * vaccines.effective & 0.17 & 0.23 & -0.15 & 0.38 \\
\hline Southern Europe * knows.ill.covid & 0.21 & 0.15 & -0.15 & 0.43 \\
\hline
\end{tabular}




\begin{tabular}{lcccc}
\hline & $\begin{array}{c}\text { Model 4 } \\
\text { (hesitancy) }\end{array}$ & \multicolumn{2}{c}{$\begin{array}{c}\text { Model 5 } \\
\text { (refusal) }\end{array}$} \\
Characteristic & $\log (\mathrm{OR})$ & p-value & $\log (\mathrm{OR})$ & p-value \\
\hline Western Europe * knows.ill.covid & 0.08 & 0.47 & -0.04 & 0.80 \\
\hline Southern Europe * was.ill.covid & -0.17 & 0.41 & -0.04 & 0.89 \\
\hline Western Europe * was.ill.covid & -0.20 & 0.20 & 0.26 & 0.21 \\
\hline Southern Europe * fears.covid & -0.04 & 0.74 & 0.05 & 0.81 \\
\hline Western Europe * fears.covid & 0.13 & 0.20 & 0.16 & 0.36 \\
\hline
\end{tabular}




\section{Mediation analysis per region}

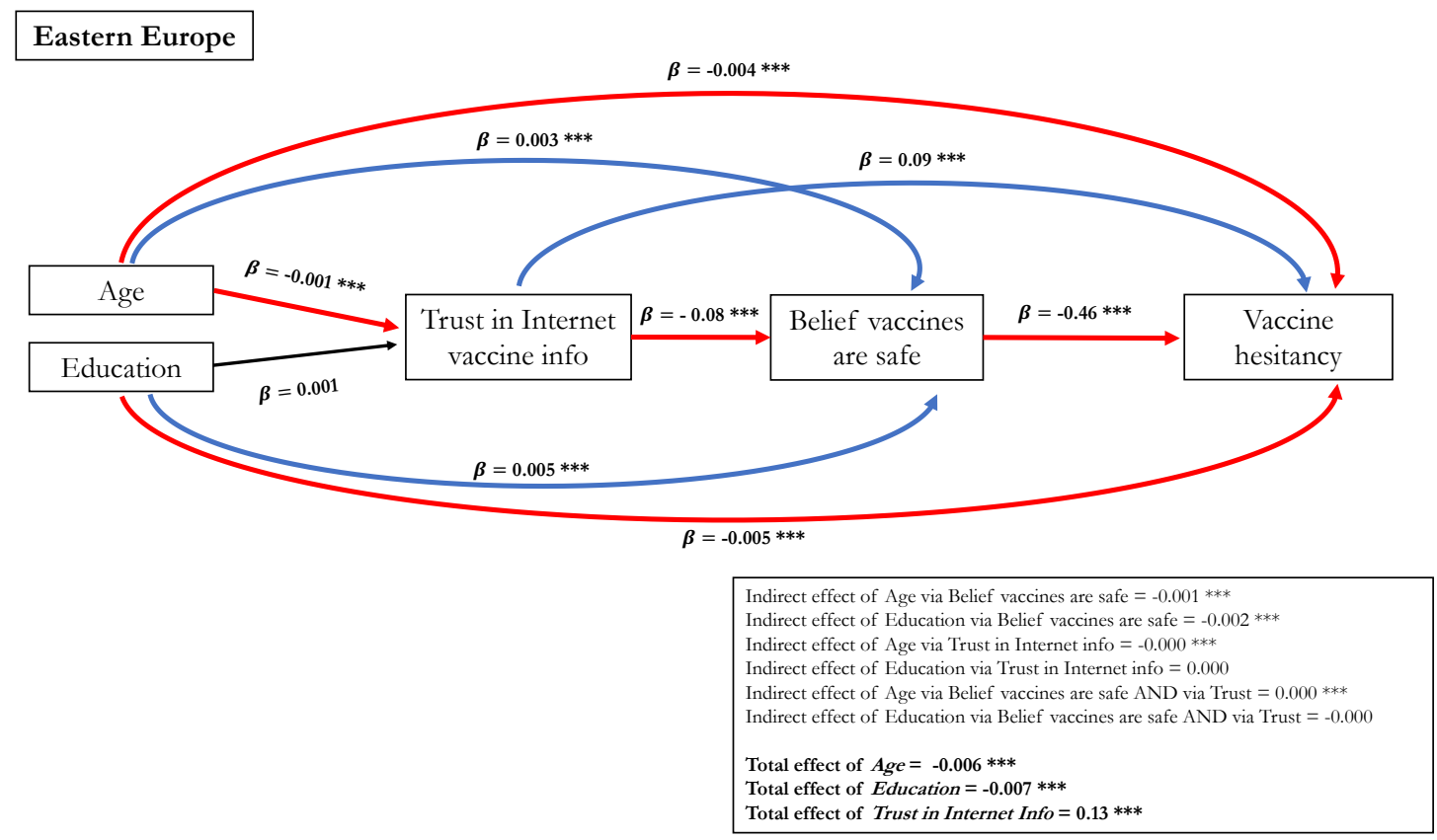

Western Europe

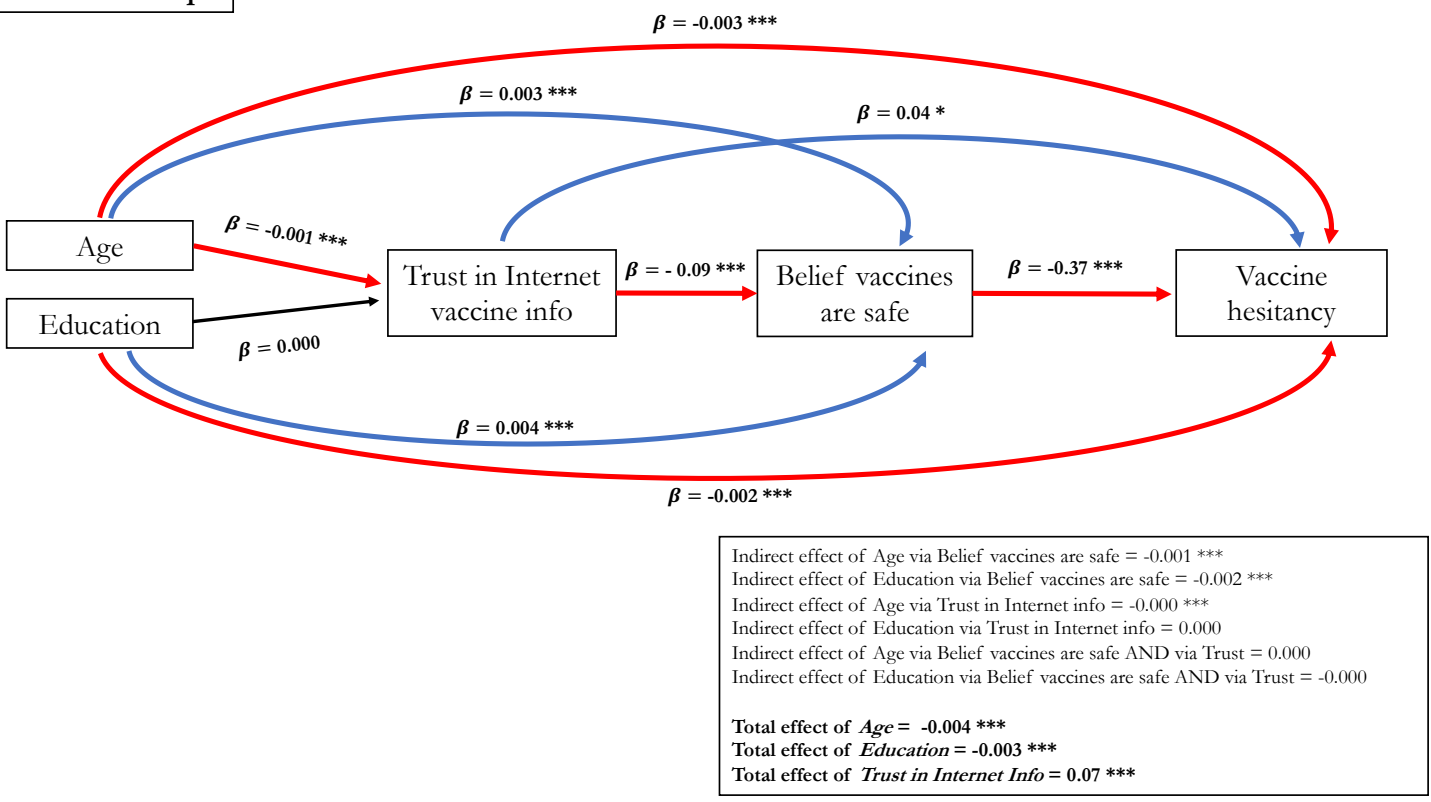




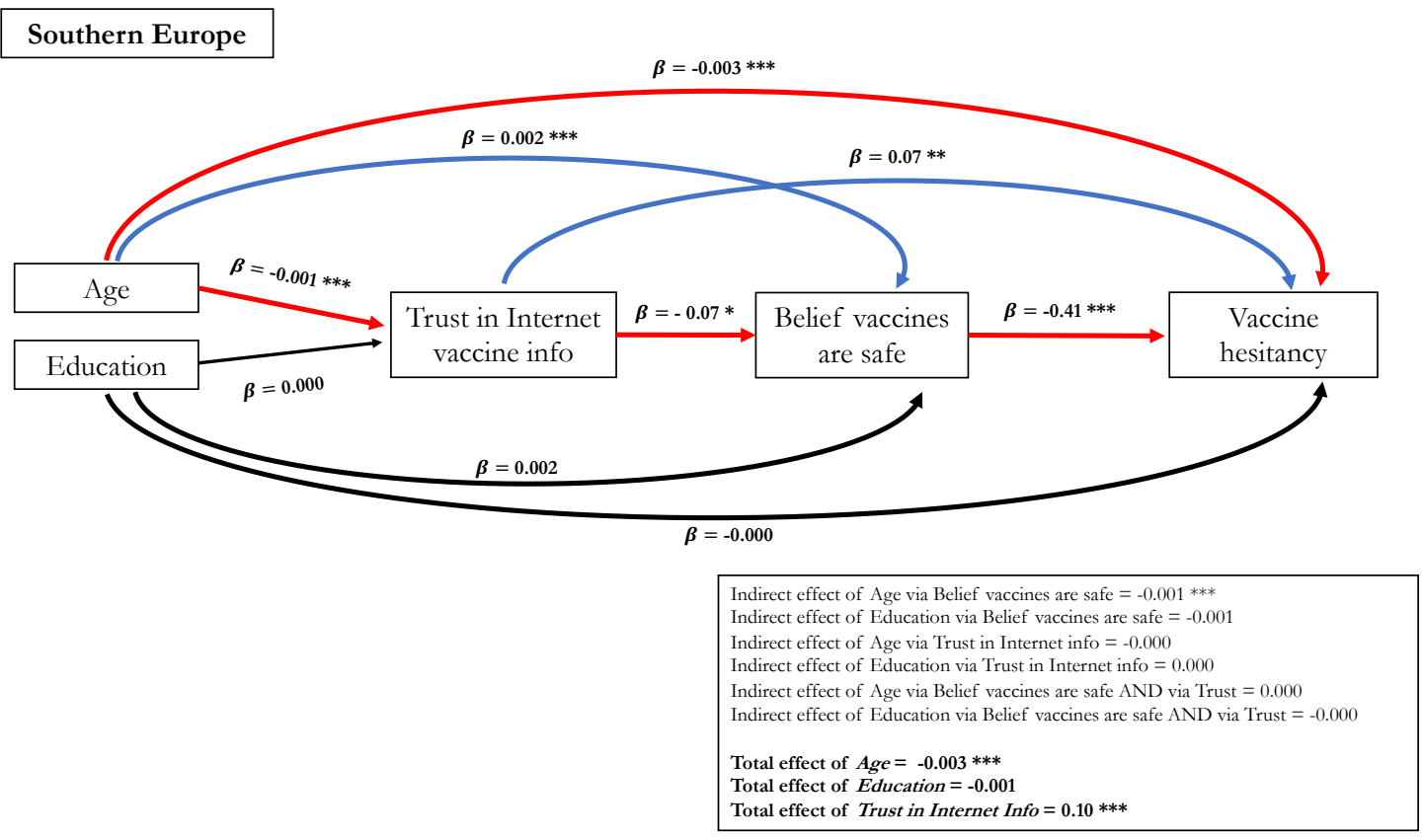

